\title{
IMIDAZOL E CATÁLISE: UM PAR PERFEITO
}

\author{
Valmir B. Silva a Elisa S. Orth ${ }^{\mathrm{a}, *,(1)}$ \\ aDepartamento de Química, Universidade Federal do Paraná, 81531-980 Curitiba - PR, Brasil
}

Recebido em 24/07/2020; aceito em 24/09/2020; publicado na web em 28/10/2020

\begin{abstract}
IMIDAZOLE AND CATALYSIS: A PERFFECT MATCH. The imidazole (IMZ) ring presents several chemical properties that turns it into a versatile acid-basic/nucleophilic catalyst. The discovery of the biological properties of histidine (amino acid with IMZ ring) instigates the study of this class of compounds. It is found in nature in several enzymes such as chymotrypsin and RNAses due to these properties. This review is focused on the catalytic role of IMZ towards the cleavage of acyl and phosphate esters and is structured in the following topics: chemical properties, biological catalysis (RNAses, phosphohistidines, chymotrypsin), intermolecular and intramolecular catalytic models and polymer and nanomaterials-based catalysts. Besides we discuss some properties such as tautomerism, stability, basicity and spectroscopic behavior, correlating with its reactivity in deacylation and dephosphorylation reactions. The main reaction mechanisms and kinetics promoted by IMZ as an acid, basic and nucleophilic catalysts are explored showing some examples. In addition, the importance of IMZ in enzymatic sites and their mechanisms and further combining properties of IMZ with some materials such as (bio)polymers, graphene, and cyclodextrines are covered. In this sense, with the wide IMZ data presented here, we are evidencing the perfect match between IMZ and catalysis.
\end{abstract}

Keywords: reaction mechanisms; deacylation; dephoshorylation; organophosphates; enzymatic models.

\section{QUÍMICA DO IMIDAZOL}

O imidazol (IMZ) foi descoberto em 1858 quando foi primeiro sintetizado por Heinrich Debus. ${ }^{1}$ IMZ é uma molécula polar (momento dipolo $3,61 \mathrm{D})^{2}$ com alta solubilidade em água $\left(633 \mathrm{~g} \mathrm{~L}^{-1}\right)^{3} \mathrm{e}$ em outros solventes polares. ${ }^{4}$ É sólido a temperatura ambiente, incolor e com elevada temperatura de fusão $\left(90{ }^{\circ} \mathrm{C}\right)$ e ebulição $\left(256{ }^{\circ} \mathrm{C}\right)$, devido às fortes ligações de hidrogênio intermoleculares. ${ }^{5}$ Estruturalmente, o IMZ é um heterociclo aromático de cinco membros contendo dois átomos de nitrogênio alternados. Ele possui seis elétrons $\pi \mathrm{em}$ orbitais p paralelos, sendo um par de elétrons do nitrogênio ligado ao hidrogênio $\left(\mathrm{N}_{1}\right.$ na Figura 1$)$, conferindo um caráter aromático à estrutura. ${ }^{6}$ Assim, tem-se a deslocalização dos elétrons levando às estruturas de ressonância, ilustradas na Figura 1. Esse caráter aromático garante a alta estabilidade química do IMZ, exemplificado, por exemplo, que mesmo em ácido clorídrico concentrado e $180^{\circ} \mathrm{C}$, sua hidrólise não ocorre. Já seu análogo não aromático, 2-imidazolina, hidrolisa facilmente em ácido clorídrico diluído sob refluxo brando. ${ }^{5}$ Referente a dados espectroscópicos, IMZ (em solução aquosa) possui absorção no UV-vis com comprimento de onda máximo em $205 \mathrm{~nm}$ $\left(\varepsilon=3720 \mathrm{~L} \mathrm{~mol}^{-1} \mathrm{~cm}^{-1}\right)$ devido à transição $\pi \rightarrow \pi^{*}{ }^{4,7}$ Quanto aos espectros de ressonância magnética nuclear (RMN) de hidrogênio, o IMZ (em $\mathrm{D}_{2} \mathrm{O}$ ) apresenta os deslocamentos químicos de 7,68 ppm $(1 \mathrm{H})$ para $\mathrm{C}_{2}$ e $7,00 \mathrm{ppm}(2 \mathrm{H})$ para o $\mathrm{C}_{4} / \mathrm{C}_{5}$. No espectro de carbono, tem-se os deslocamentos $135,90 \mathrm{ppm}(\mathrm{CH})$ para $\mathrm{C}_{2}$ e $121,50 \mathrm{ppm}$ (CH) para o $\mathrm{C}_{4} / \mathrm{C}_{5}{ }^{8}$

O IMZ possui o tautomerismo apresentado na Figura 2, mostrando que os nitrogênios $\mathrm{N}_{1}$ e $\mathrm{N}_{3}$ são equivalentes, ou seja, ora o nitrogênio $\mathrm{N}_{1}$ está ligado ao hidrogênio e seu par de elétrons comprometido com a aromaticidade ora o nitrogênio $\mathrm{N}_{3}$ tem o mesmo comportamento. Assim, tem-se para o IMZ dois tautômeros idênticos estruturalmente. Por outro lado, para IMZ substituídos, pode haver distinção, por exemplo, 4(5)-metilimidazol (4(5)-MEI), Figura 2. O tautomerismo do IMZ foi descoberto por Kaiser em 1888, que ao realizar a reação de redução do ácido 3-nitro-4-acetamidobenzóico ou do ácido

*e-mail: elisaorth@ufpr.br
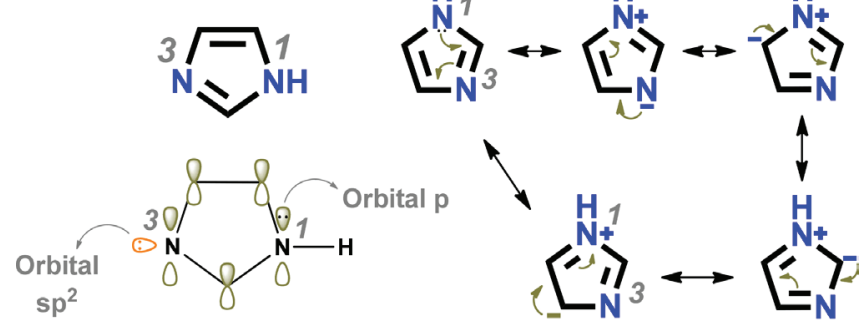

Figura 1. Estrutura do IMZ, orbitais atômicos e suas estruturas canônicas ${ }^{6,9}$

4-nitro-3-acetamidobenzóico, obteve o mesmo produto benzimidazol, conforme mostrado na Figura $3 .{ }^{5}$ Vale ressaltar que estudos com IMZ substituídos (exceto $N$-substituídos que não possuem tautomerismo) permitiram confirmar a existência dos tautômeros, reiterando que os nitrogênios $\mathrm{N}_{1}$ e $\mathrm{N}_{3}$ do IMZ (Figura 2) são idênticos. ${ }^{10,11}$ Outra característica é que o tautomerismo influencia nas diferentes razões entre isômeros de produtos obtidos de reações com derivados do IMZ que possuem tautômeros, e.g. 4(5)-substituído. Por exemplo, a metilação (com $\mathrm{Me}_{2} \mathrm{SO}_{4}$ ) do 4(5)MEI e 4(5)-nitroimidazol levam a uma proporção 1:2,2 e 350:1, respectivamente para os isômeros 1,5- e 1,4-substituídos. ${ }^{5}$ Ou seja, a reatividade do IMZ é afetada pelo tautomerismo, conforme será exemplificado mais adiante também.

(A)

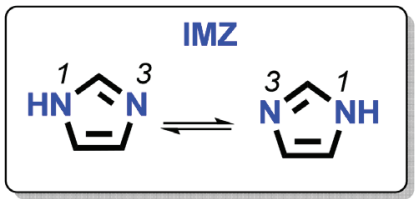

Figura 2. Tautômeros simétricos do IMZ (A) e tautômeros assimétricos do 4(5) $M E I(B)$

Para justificar a equivalência dos nitrogênios conforme mostrado nas Figuras 2 e 3, deve-se considerar o transporte do hidrogênio entre 

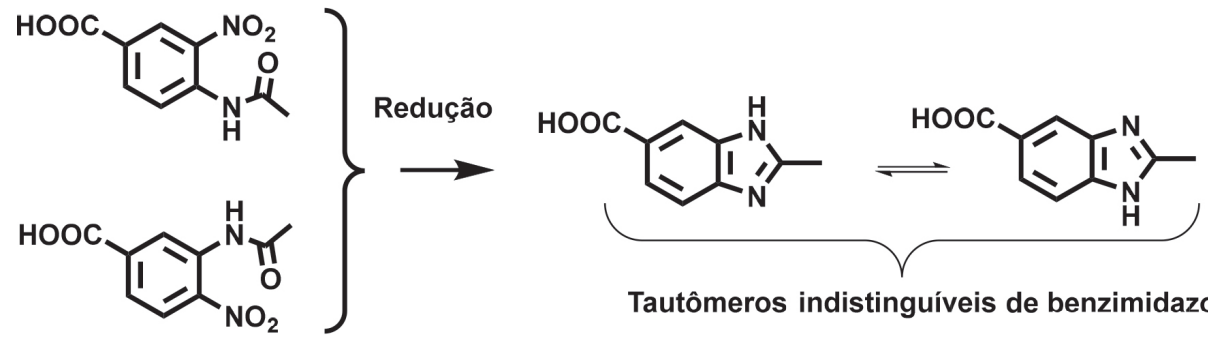

Tautômeros indistinguíveis de benzimidazol

Figura 3. Redução do ácido 3-nitro 4-acetamidobenzóico e do ácido 4 nitro 3-acetamidobenzóico 5

os nitrogênios, o que tem sido alvo de inúmeros estudos. Acreditase que a transferência ocorre por uma combinação intermolecular e intramolecular. ${ }^{12}$ No mecanismo intramolecular, apesar de evidências que desfavorecem esse caminho, como efeito estérico, alguns autores confirmam esse transporte por espectroscopia Raman. ${ }^{12}$ De fato, muitos estudos descrevem uma maior contribuição do mecanismo intermolecular, apesar do intramolecular não ser descartado. No mecanismo intermolecular, as favoráveis interações de ligação de hidrogênio levam a longas cadeias de moléculas de IMZ alinhadas, e ocorre o transporte do hidrogênio do nitrogênio de uma molécula de IMZ para o nitrogênio de outra molécula de IMZ vizinha, ${ }^{13-19}$ conforme mostrado na Figura 4. O tautomerismo apresentado na Figura 4 pode ser estendido para outras estruturas de ressonância na Figura 1 e por isso, considera-se que há uma contribuição da deslocalização de carga e transferência de hidrogênio no tautomerismo do IMZ. ${ }^{20,21}$

$\mathrm{O}$ equilíbrio de ionização do IMZ neutro é bastante singular devido ao seu caráter anfótero, pois ele pode atuar como ácido $\left(\mathrm{p} K_{\mathrm{a}}=14,5\right)$ ou base ( $\left.\mathrm{p} K_{\mathrm{aH}}=7,0\right)$, conforme apresentado na Figura $5 .{ }^{6}$ A formação da espécie aniônica do IMZ ocorre em condições fortemente básicas ( $\mathrm{p} K_{\mathrm{a}}$ 14,5), portanto a espécie aniônica do IMZ é uma base relativamente forte. Já a protonação da espécie neutra, com $\mathrm{p} K_{\mathrm{aH}}$ próximo da neutralidade $(7,0)$ garante que sua espécie ácida $\mathrm{IMZH}^{+}$e neutra estejam numa proporção de $\sim 50 \%$ em solução aquosa em $\mathrm{pH}$ 7. Vale ressaltar que a protonação do IMZ neutro ocorre no nitrogênio $\mathrm{N}_{3}$ que possui par de elétrons livre em orbital $\mathrm{sp}^{2}$, visto que o outro nitrogênio $\left(\mathrm{N}_{1}\right)$ possui par de elétrons envolvido com a conjugação do anel. Assim, sua protonação é desfavorável, pois levaria a uma espécie não aromática, enquanto a protonação no nitrogênio $\mathrm{N}_{3}$ leva a uma espécie catiônica aromática (Figura 5). O mesmo ocorre com a piridina, visto que a protonação ocorre no nitrogênio com par de elétrons livre em orbital $\mathrm{sp}^{2}$ resultando também em uma espécie aromática. Já no caso do pirrol, o par de elétrons livre do nitrogênio está deslocalizado no anel aromático e sua protonação ocorre no carbono do anel, levando a um cátion não aromático, o que é extremamente desfavorável. ${ }^{6}$ Assim, muitos autores postulam que os nitrogênios $\mathrm{N}_{1}$ e $\mathrm{N}_{3}$ correspondem ao nitrogênio tipo pirrol e tipo piridina, respectivamente. ${ }^{22,23}$

Com relação ao $\mathrm{p} K_{\mathrm{aH}}$ do IMZ, é menos básico que o análogo não aromático, imidazolina $\left(\mathrm{p} K_{\mathrm{a}}^{+\mathrm{NH}}=11\right)$, no entanto, mais básico que piridina $\left(\mathrm{p} K_{\mathrm{a}}^{+\mathrm{NH}}=5,5\right)$ ou pirrol $\left(\mathrm{p} K_{\mathrm{a}}^{+\mathrm{NH}}=-4\right)$. A basicidade anormal do IMZ é atribuída a baixa eletronegatividade dos nitrogênios e à estabilização da carga positiva da espécie protonada entre os nitrogênios equivalentes. ${ }^{22}$ Espera-se que IMZ seja menos básico que imidazolina, pois a aromaticidade é conhecida por diminuir a basicidade de aminas, devido ao seu caráter retirador de elétrons (e.g. piperidina tem $\mathrm{p} K_{\mathrm{aH}} 11,2$, maior que piridina). No caso do pirrol, conforme discutido, devido ao par de elétrons do nitrogênio estar deslocalizado no anel, o nitrogênio é muito ácido e sua protonação é desfavorável pois leva a uma espécie não aromática. Finalmente, a maior acidez da piridina se deve por esta apresentar apenas um nitrogênio para estabilizar a carga positiva, em contraste com IMZ que possui dois nitrogênios onde a carga está deslocalizada (Figura 5). ${ }^{24}$ Conforme esperado, o $\mathrm{p} K_{\mathrm{aH}}$ do IMZ pode ser substancialmente afetado por grupos substituintes no anel. Por exemplo, 4(5)MEI possui $\mathrm{p} K_{\mathrm{aH}}=7,52$ devido ao efeito doador do grupo metila, aumentando a basicidade. Já grupos retiradores de elétrons aumentam a acidez, por exemplo, o 2-fenilimidazol e 4(5)-bromoimidazol possuem $\mathrm{p} K_{\mathrm{aH}}=6,39$ e $\mathrm{p} K_{\mathrm{aH}}=3,60$, respectivamente..$^{5}$

A reatividade do IMZ está intrinsicamente relacionada à sua especificidade estrutural, sendo que se espera que o ataque<smiles></smiles>

Figura 4. Mecanismo intermolecular de transferência de próton na molécula de IMZ ${ }^{15}$
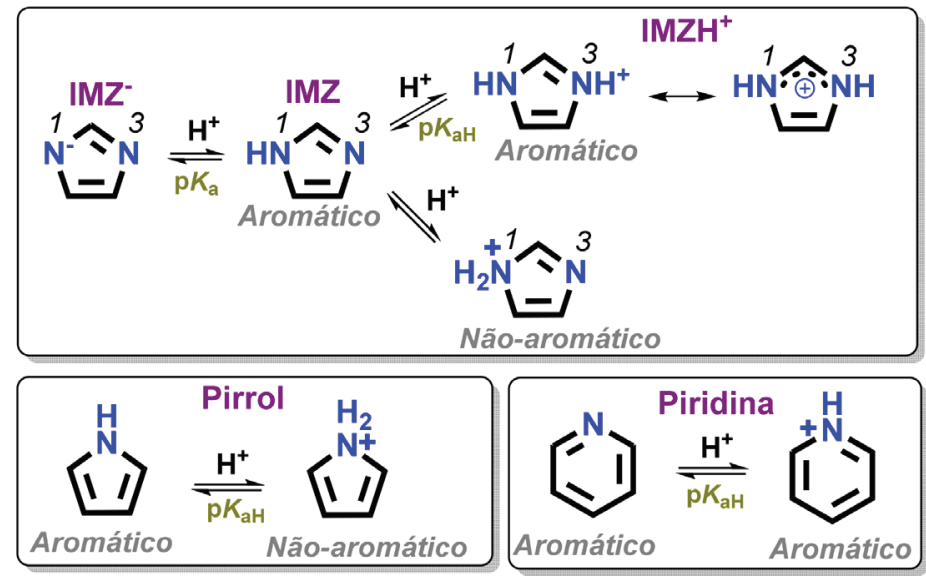

Figura 5. Equilibrios ácido-base para a molécula de IMZ, pirrol e piridina ${ }^{6}$ 
nucleofílico ocorra preferencialmente pelo nitrogênio $\mathrm{N}_{3},{ }^{22}$ entretanto, os pares de elétrons do anel também podem agir como nucleófilos, como em reações com sais de arildiazônio. ${ }^{25}$ Para o caso da síntese de derivados de IMZ, as abordagens são diversificadas na literatura: a partir de compostos dicarbonílicos, ${ }^{26,27}$ frutose, ${ }^{28}$ ciclização de compostos aminocarbonílicos, ${ }^{29}$ a partir do próprio anel de IMZ e da histidina, ${ }^{30-32}$ rearranjos, ${ }^{25,33}$ reações multicomponentes, ${ }^{34,35}$ e muitos outros que fogem do objetivo dessa revisão.

Ainda, a química peculiar do IMZ garante sua versatilidade catalítica pois pode atuar como catalisador, acelerando reações químicas e sendo recuperado no final, ou seja, não sendo consumido. Em sua forma protonada pode atuar como catalisador ácido e na forma neutra ou aniônica pode atuar como catalisador básico ou nucleófilo. De fato, a natureza tem nos mostrado que IMZ e catálise são um par perfeito, visto que muitos sítios enzimáticos possuem grupos IMZ que exercem múltiplas funções catalíticas com extrema eficiência. Não surpreende que o design de enzimas artificiais e outros modelos miméticos/não-miméticos tem se beneficiado de estruturas derivadas do IMZ.

\section{IMIDAZOL PARA CATÁLISE: UMA LIÇÃO DOS SISTEMAS BIOLÓGICOS}

O IMZ é conhecido por sua fundamental importância biológica e terapêutica, conforme ilustrado na Figura 6. Nos sistemas biológicos, ele se encontra na forma do aminoácido histidina, compondo inúmeros sítios enzimáticos. Ainda, na forma da histamina, induz processos imunológicos, ${ }^{36-38}$ e compõe as bases adenosina e guanina dos ácidos nucléicos. ${ }^{22}$ Pelo viés terapêutico, é conhecida a atividade farmacológica de muitos derivados de IMZ, por exemplo como antifúngica, antitumoral, antibiótica, anti-histamínica, anticoagulante, anti-inflamatória, antibacteriana, antiviral, antidiabética, antimalárica, analgésica, gene delivery, entre outros. ${ }^{2,39-41}$ Realmente, existem muitos fármacos derivados de IMZ amplamente comercializados como metronizadol, cetoconazol, cimetidina, miconazol, omeprazol, dacarbazina, metimazol, entre outros. ${ }^{41}$
Nessa revisão, o enfoque principal será o papel catalítico do IMZ, especificamente em reações de desfosforilação e desacilação, visto que estão entre as mais encontradas nos processos biológicos ${ }^{42-46}$ como o armazenamento e transmissão de informação genética (DNA e RNA), ${ }^{47,48}$ processos de sinalização e regulação da atividade celular, ${ }^{49,50}$ provimento de energia através de anidridos fosfóricos (ATP), ${ }^{43,51,52}$ metabolismo, entre outros. ${ }^{53}$ No contexto das enzimas biológicas, a fosfotriesterase chama a atenção por conseguir hidrolisar de forma muito eficiente triésteres de fosfato, sendo que os mesmos não são encontrados na natureza, sugerindo que a enzima evoluiu pelo demasiado uso dos pesticidas organofosforados nas lavouras. ${ }^{54,55}$ Além dos processos biológicos, diversas estruturas baseadas em IMZ (derivados, enzimas biológicas e artificiais, nanocompósitos etc) são estudadas para a desativação/sensoriamento de compostos tóxicos como armas químicas e pesticidas organofosforados devido à alta atividade catalítica. ${ }^{8,56-58}$

De maneira geral, a desfosforilação e desacilação envolvem a transferência do grupo fosforila e acila de ésteres de fosfato e ésteres carboxílicos, respectivamente, conforme ilustrado na Figura 7. Essa transferência está exemplificada com um nucleófilo $(\mathrm{Nu})$ e envolve a eliminação de um grupo de saída (-OR) e formação de uma espécie fosforilada ou acilada, que em geral é conhecida por ser instável, se hidrolisando em água. Ainda, a natureza do éster é importante nessas reações. No caso dos ésteres carboxílicos, em reações com nucleófilos como a hidroxila, a reatividade é influenciada pelo grupamento $-\mathrm{OR}_{1}$ e pelo grupo -R ligado diretamente a carboxila (Figura 7), sendo que, de forma geral, quanto menor o $\mathrm{p} K_{\mathrm{a}}$ do grupo de saída $-\mathrm{OR}_{1}$ e do ácido carboxílico formado, mais reativo será o éster. ${ }^{59}$ Já os fosfatos podem ocorrer como mono, di ou triésteres dependendo do número de substituintes (Figura 7) e, em geral, a reatividade segue a ordem triéster>diéster>monéster. Os mono e diésteres de fosfato ocorrem naturalmente nos sistemas biológicos, enquanto os triésteres são sintéticos, com grande aplicação como armas químicas, retardantes de chama, pesticidas e inseticidas. ${ }^{60,61}$ Os substituintes ligados aos ésteres afetam diretamente sua reatividade e quanto melhor o grupo de saída (menor $\mathrm{p} K_{\mathrm{a}}$ do grupo de saída), mais reativo é o éster. ${ }^{62} \mathrm{De}$ fato,

Funções biológicas Funções terapêuticas

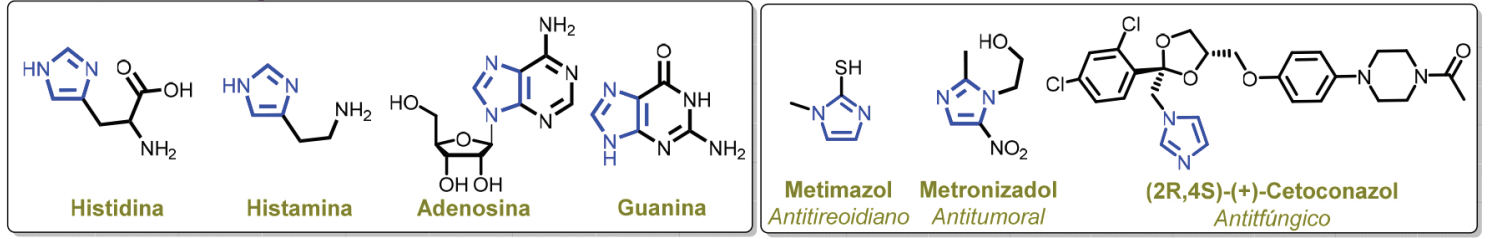

Figura 6. Derivados de IMZ com importantes funções biológicas ou terapêuticas ${ }^{4}$
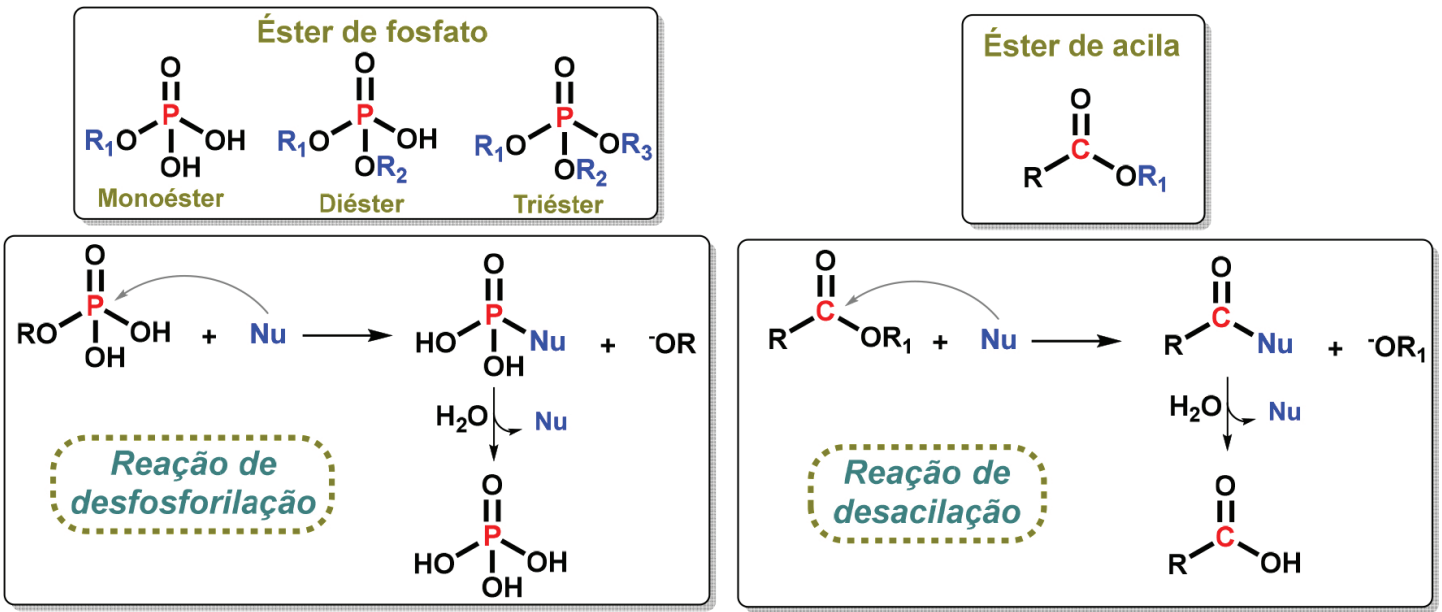

Figura 7. Esquema geral de reações de esteres fosfóricos e carboxílicos com nucleófilos 
os ésteres de fosfato e acila são conhecidos pela alta estabilidade ${ }^{63} \mathrm{o}$ que é importante e desejável para suas funções biológicas. Reações de importância biológica que envolvem quebra da ligação P-O e C-O estão estimadas na ordem de 5-13 milhões de anos, ${ }^{63}$ na ausência de enzimas, podendo chegar à ordem de bilhões de anos para o DNA, ${ }^{64}$ superior à idade da Terra. A capacidade das enzimas de acelerar reações tão desfavoráveis, no entanto, fundamental à sobrevivência humana, justifica o interesse em estudar as enzimas biológicas, exímios catalisadores. Nesse contexto, o IMZ se destaca por constituir inúmeros sítios ativos enzimáticos na forma do resíduo histidina.

De maneira geral, a atuação do grupo IMZ nos sistemas biológicos ocorre por catálise ácida-básica geral e nucleofílica. A Figura 8 ilustra os possíveis caminhos catalíticos para espécie neutra e protonada do IMZ envolvendo um centro eletrofílico " $X$ " que pode ser " $P$ " ou "C" para éster de fosfato ou acila, respectivamente. Ainda, $\mathrm{RO}$ e $\mathrm{Nu}$ correspondem ao grupo de saída e um nucleófilo, respectivamente. Como catalisador ácido geral, o $\mathrm{IMZH}^{+}$atua como ácido facilitando a saída do grupo $\mathrm{RO}^{-}$através de uma transferência de hidrogênio (ROH melhor grupo de saída em meio ácido). ${ }^{65} \mathrm{Na}$ forma neutra, IMZ pode atuar como catalisador nucleofílico atacando o centro eletrofílico e levando a um intermediário fosforilado ou acilado, que é consecutivamente hidrolisado e o grupo IMZ regenerado. ${ }^{50}$ Portanto, IMZ catalisa a clivagem da ligação X-O. Por fim, o IMZ também pode atuar como catalisador básico-geral, assistindo o ataque de um nucleófilo (Nu-H) sobre o centro eletrofílico, abstraindo um próton e assim, aumentando sua nucleofilicidade..$^{48,66}$

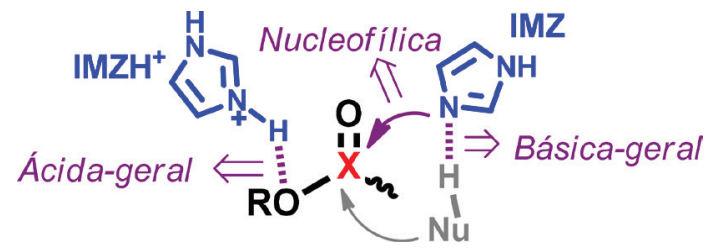

Figura 8. Multiplas catálises promovidas pelo IMZ: ácida, básica e nucleofilica ${ }^{9,67}$

\section{Atuação catalítica do imidazol nos sítios enzimáticos}

\section{Ribonucleases}

O aminoácido histidina exerce papel fundamental em diversos sítios ativos enzimáticos, por exemplo, nas ribonucleases, fosfotriesterases, quinases e quimotripsinas. ${ }^{55,68,69}$ Especificamente, a ribonuclease $\mathrm{A}$ (RNase $\mathrm{A}$ ) apresenta um mecanismo de atuação em reações de desfosforilação bastante elegante de múltiplas catálises envolvendo dois grupos histidinas. ${ }^{70}$ A RNase A, responsável pela quebra do RNA, foi a primeira enzima que teve seus aminoácidos sequenciados, ${ }^{71}$ bem como seus sítios catalíticos identificados e é considerada uma das enzimas mais estudadas do século 20 (projetado para século 21 também). ${ }^{72}$ Ela é uma enzima pequena com cerca de 100-150 aminoácidos ${ }^{48}$ cuja forma de atuação está principalmente relacionada aos resíduos His-12 e His-119 no sítio ativo principal. Dois mecanismos são propostos para a RNase A: um ácido-base geral concertado e um "tipo triéster", conforme resumido na Figura $9 .{ }^{73}$ No clássico mecanismo ácido-base geral, ${ }^{48}$ a reação ocorre em duas etapas. Na primeira etapa, o resíduo His-119 atua como ácido geral ativando a saída do grupo do $\mathrm{RO}^{-}$, enquanto a His-12 atua como catalisador básico geral assistindo o ataque de uma hidroxila no fosfato, levando a um intermediário cíclico. $\mathrm{Na}$ segunda etapa, de hidrólise do intermediário cíclico, o papel das histidinas inverte onde a His-119 ativa o ataque da água por catálise básica geral e a His-12, como ácido geral, protona o grupo de saída. No mecanismo "tipo triéster" ocorre a protonação do oxigênio da fosforila levando a um estado de transição similar (ou intermediário) tipo fosforano semelhante ao de reações de triésteres. ${ }^{44,49}$ Existem outras ribonucleases como RNase $\mathrm{T}^{74}$ e barnase, ${ }^{75}$ que atuam por um mecanismo análogo de ácido-base geral, onde o resíduo Glu-58 atua como base geral no lugar da His-12.

Existe uma grande discussão ${ }^{48,76,77}$ com relação à forma de atuação das RNase A, mas em geral evidências experimentais apontam para o mecanismo clássico ácido-base geral. Por exemplo, o perfil de $\mathrm{pH}$ em forma de sino, dados cristalográficos, efeitos isotópicos cinéticos com ${ }^{18} \mathrm{O}$ e análises de tio-efeitos em que a substituição do oxigênio da fosforila por enxofre não reduz a velocidade da reação, como esperado se ocorresse pelo mecanismo "tipo triéster". ${ }^{77,78}$

Estudos mostram que as RNase A são promissoras no diagnóstico e tratamento terapêutico, como câncer. Isso porque a quantidade de RNases aumenta no corpo humano quando ocorre disfunções como doenças, o que pode ser regulada por ativadores ou inibidores (i.e. fármacos).$^{79}$ Ainda, a citotoxicidade das RNase A frente a células cancerígenas tem mostrado potencial como agente terapêutico, por ser biocompatível e causar menor efeito colateral que os agentes quimioterápicos mais usuais..$^{80}$
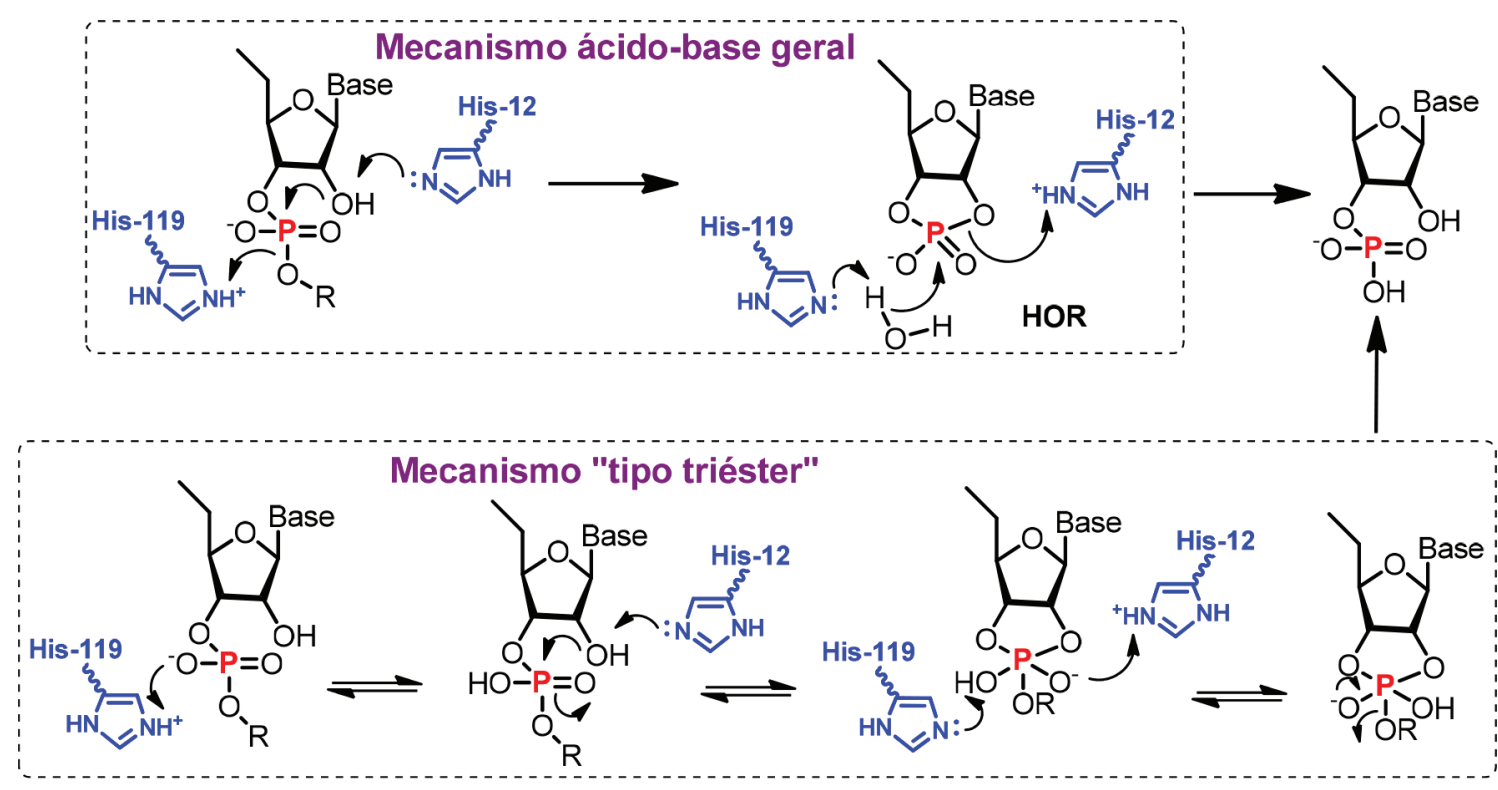

Figura 9. Proposta de mecanismos de reação para RNase A: ácido-base versus triéster ${ }^{73}$ 


\section{Fosfohistidinas}

As reações reversíveis de fosforilação com proteínas são chave em inúmeros processos de sinalização e regulação celular. ${ }^{81}$ Esses processos podem ocorrer pela $O$-fosforilação levando a fosfoserina, fosfotreonina e fosfotirosina ou pela $N$-fosforilação, formando fosforamidatos. ${ }^{82}$ Nos sistemas biológicos, os diferentes tautômeros da histidina, 1-histidina (1HIS) e 3-histidina (3HIS) levam aos fosforamidatos 3-fosfohistidina (3FOSHIS) e 1-fosfohistidina (1FOSHIS), respectivamente, conforme mostrado na Figura 10.50,83 Estudos apontam que o isômero 3HIS é preferido nos sistemas biológicos ${ }^{84}$ e ainda que 1FOSHIS é menos estável, podendo até se converter na 3FOSHIS. ${ }^{85}$ Assim, a preferência pelo isômero 3HIS nos sistemas biológicos, que leva ao instável fosforamidato 1FOSHIS, é consistente com o papel das fosfohistidinas de promover reações de fosforilações reversíveis e rápidas.

Embora os aminoácidos $O$-fosforilados em sistemas biológicos estejam vastamente descritos na literatura e já tenham sido detectados nos anos $1930,{ }^{50,86} \mathrm{o}$ interesse pelos $N$-fosforilados surgiu em meados dos anos 1990 com o advento de técnicas que permitissem detectar os fosforamidatos. ${ }^{87,88}$ Apesar da maior ocorrência dos $O$-fosforilados nos sistemas biológicos, i.e. $50 \%$ dos fosfoaminoácidos em contraste a $6 \%$ das fosfohistidinas, ${ }^{82} \mathrm{o}$ interesse pelos fosforamidatos tem crescido devido ao seu potencial terapêutico em diversas doenças.

Para cumprir seu papel de promover reações reversíveis e rápidas de desfosforilação, as fosfoshistidinas são conhecidamente instáveis. A ligação P-N (fosforamidato) na fosfohistidina é altamente instável (alto valor de $\Delta \mathrm{G}$ ), transferindo rapidamente o grupo fosforila para outras moléculas, peça chave em processos de sinalização. A hidrólise das fosfohistidinas apresenta um $\Delta \mathrm{G}^{\circ}$ bem negativo (-12 a $-14 \mathrm{kcal} \mathrm{mol}^{-1}$ ), favorecendo sua espécie não fosforilada. ${ }^{83}$ Por exemplo, em meio ácido ( $\mathrm{HCl} 1 \mathrm{~mol} \mathrm{~L}^{-1}$ ), a 1-FOSHIS tem tempo de meia-vida de $18 \mathrm{~s}$, enquanto que em $\mathrm{pH} 7$ e 8 , chega a 1 min e 34 min, respectivamente. ${ }^{89}$ Devido à alta labilidade da ligação $\mathrm{P}-\mathrm{N}$ em meio ácido, mais habitual nas análises de fosforilação de proteínas, por muito tempo as fosfohistidinas não eram detectadas. Isso só foi possível com técnicas mais avançadas como cromatografia em fase reversa, $\mathrm{RMN}$, marcação isotópica $\left({ }^{32} \mathrm{P}\right)$ e espectrometria de massas (ESI-MS e MALDI-TOF-MS). ${ }^{50,90}$

A fosforilação reversível de aminoácidos é promovida nos sistemas biológicos pelas enzimas quinases e fosfatases ${ }^{53,91,92}$ e um dos processos mais pioneiros (e compreendidos) é o sistema de dois componentes nos processos de sinalização de bactérias, envolvendo fosfohistidinas. ${ }^{90}$ Esse processo também foi observado em algumas
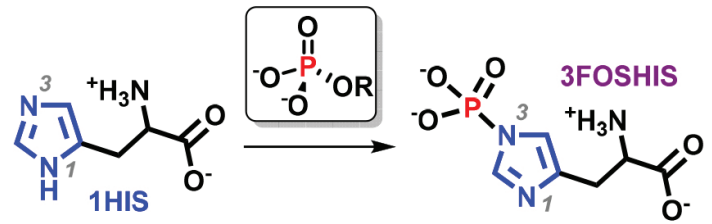

plantas e leveduras, mas não há evidências em vertebrados e tem particular potencial no desenvolvimento de novos antibióticos, visto envolver os processos de resistência das bactérias. ${ }^{93} \mathrm{O}$ sistema de dois componentes é composto por dois componentes principais: a quinase de histidina e uma proteína reguladora de resposta, que está resumido na Figura $11 .^{50} \mathrm{O}$ processo inicia com um estímulo externo que aciona o sítio da quinase para fosforilar uma histidina, utilizando ATP como doador do grupo fosforila. Em seguida, a fosfohistidina transfere o grupo fosforila para um resíduo de aspartato do sítio da proteína reguladora de resposta, que então ativa sua resposta celular, tal como mudança no movimento dos flagelos, entre outros. ${ }^{90}$ Devido à natureza lábil das fosfohistidinas, esses processos de fosforilação e desfosforilação não requerem uma fosfatase e ocorrem rapidamente, funcionando como um dispositivo de ligar/desligar. ${ }^{50}$ Existem sistemas de multi-componentes que ocorrem com múltiplas fosforilações, e o papel das fosfohistidinas é fundamental, ${ }^{94}$ visto que a sua formação é altamente reversível, comparado com outros fosfoaminoácidos. ${ }^{95}$

Enquanto nas bactérias a função das fosfohistidinas está consolidada, seu papel nos vertebrados ainda não está esclarecido e seus estudos são recentes. ${ }^{50,81}$ A nucleosídeo-difosfato-quinase foi a primeira enzima onde se detectou a participação das fosfoshistidinas nos vertebrados, em 1968. ${ }^{96}$ A correlação das fosfohistidinas com processos de sinalizações importantes, e.g. G-proteínas, ${ }^{97}$ foi próximo de 1990 e a caracterização estrutural da quinase e fosfatase, envolvidas no processo ocorreram apenas no ano de $2003 .{ }^{98}$ Não obstante, os processos de sinalização através de reações reversíveis de fosforilações da histidina parecem ser universais, justificando a importância em compreender esses processos, que são particularmente promissores na compreensão do mecanismo de resistência a antibióticos das bactérias e no desenvolvimento de novos fármacos. ${ }^{99-101}$

Outro interesse pelas fosfohistidinas pelo viés terapêutico é no caso de uma fosforilação anormal que pode estar correlacionado a muitas doenças, como o câncer e doenças inflamatórias crônicas. ${ }^{102}$ Nesse contexto, o desenvolvimento de inibidores de quinases de histidina tem potencial e alguns estudos envolvendo detecção de câncer tem se mostrado bem sucedidos, ${ }^{94}$ no entanto, a dificuldade em obter anticorpos de fosfohistidina atrasa significativamente os avanços nessa área. ${ }^{100,103}$

\section{Quimotripsinas}

Enquanto nas reações enzimáticas de desfosforilação, a histidina pode atuar tanto como catalisador nucleofílico e ácido-base geral, nas reações de desacilação, o papel da histidina em geral é de

Figura 10. Fosforilação da histidina: tautômeros de posição ${ }^{50}$
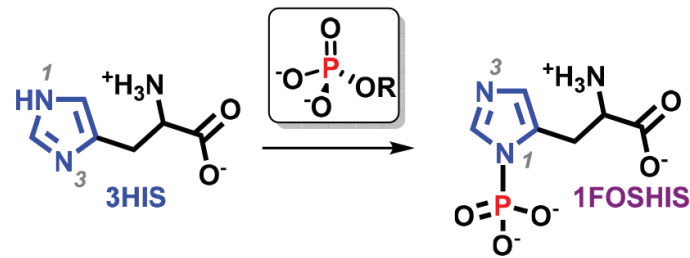

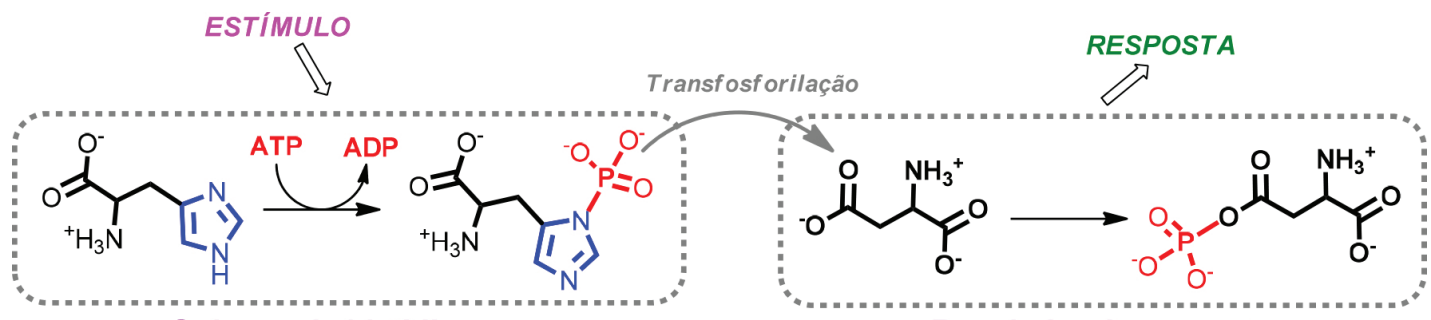

Quinase de histidina

Regulador de resposta

Figura 11. Representação do "sistema de dois componentes" em bactérias ${ }^{50}$ 


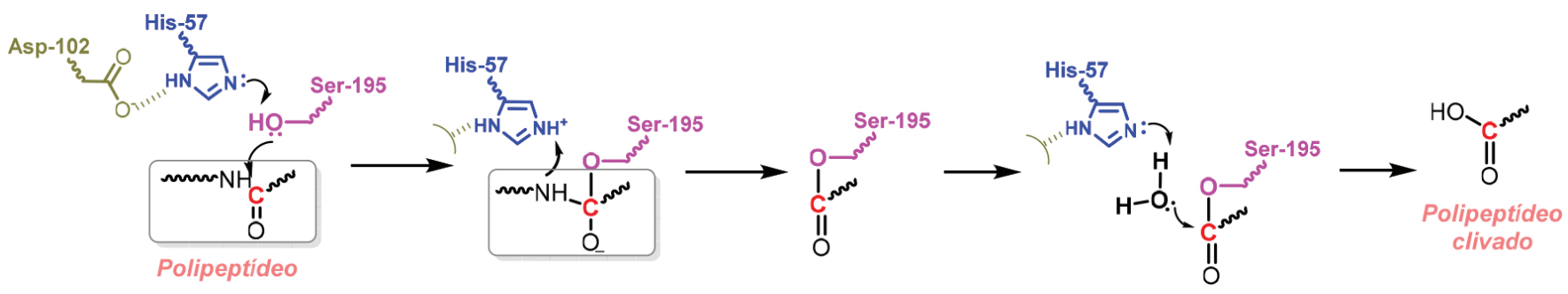

Figura 12. Mecanismo de atuação da enzima $\alpha$-quimotripsina na clivagem de peptídeos ${ }^{105,106}$

ácido-base-geral, por exemplo, a $\alpha$-quimotripsina. A quimotripsina é uma enzima digestiva que contem 245 aminoácidos e atua na clivagem de ligação peptídica. ${ }^{104}$ Sua forma de atuação está ilustrada na Figura 12 onde envolve principalmente os resíduos His-57, serina (Ser-195) e ácido aspártico (Asp-102), formando a tríade catalítica. Inicialmente, os resíduos Asp-102 e His-102 atuam como catalisador básico-geral auxiliando o ataque nucleofílico do grupo alcóxido da Ser-195 no carbono eletrofílico do polipeptídeo. Em seguida, o intermediário tetraédrico formado se decompõe levando à enzima acilada, se beneficiando de uma catálise ácida-geral da His-57. Por fim, ocorre a desacilação da enzima pelo ataque nucleofílico da água onde a His-57 atua como catalisador básico-geral. ${ }^{69,105,106}$

\section{MODELOS MIMÉTICOS E NÃO MIMÉTICOS CONTENDO IMIDAZOL}

A mimetização das enzimas é extremamente importante, pois ampara sua elucidação mecanística e permeia o desenvolvimento de enzimas artificiais e catalisadores análogos. Devido à sua complexidade estrutural, tem-se buscado modelos que imitam o sítio ativo das enzimas através de modelos miméticos e não miméticos. Apesar dessa bio-inspiração, muitas reações catalíticas promovidas por IMZ podem ter outra aplicação além da biológica/terapêutica, como rotas sintéticas, entre outras. Os modelos miméticos procuram imitar diversas particularidades de uma enzima, combinando múltiplos efeitos, como catálise e atração hidrofóbica. ${ }^{107,108}$ Já modelos não-miméticos em geral são moléculas estruturalmente mais simples e buscam compreender uma característica específica da enzima, por exemplo um tipo de catálise. ${ }^{109}$ Ainda, os modelos podem ser inter- ou intramoleculares, quando os grupos reativos reagem por moléculas diferentes ou estão ancorados na mesma estrutura (e.g. moléculas, polímeros, enzimas, nanomateriais, etc), respectivamente. Em geral, os modelos intramoleculares são mais eficientes que as intermoleculares, justificado principalmente pela teoria espaço-temporal de Menger, ${ }^{110}$ que atribui fatores como ângulo, entropia e proximidade para a eficiência catalítica intramolecular. Uma das ferramentas para a determinação dos tipos de catálise promovida pelo IMZ e seus derivados que serão discutidos a seguir é a construção de perfis cinéticos de $\mathrm{pH}$ (constante de velocidade $v s$ $\mathrm{pH}$ ), em que os mesmos evidenciam as regiões que o IMZ apresenta diferentes tipos de catálise (mostrado na Figura 8) permitindo distinguir entre suas formas de atuação. A Figura 13 exemplifica os perfis cinéticos típicos de $\mathrm{pH}$ para uma catálise ácida, básica, bifuncional ácida-básica e a nucleofílica, para os casos de reações de desacilação, ${ }^{111,112}$ mas que seguem analogamente os mesmos perfis em reações de desfosforilação. ${ }^{8,113}$ Nesse gráfico é possível observar em quais faixas de $\mathrm{pH}$ (analisado entre $\mathrm{pH}$ 5-9) o IMZ tem sua atividade pronunciada, sendo que em valores de $\mathrm{pH}$ acima do $\mathrm{p} K_{\mathrm{aH}}$ prevalece a espécie neutra do IMZ. Nesse caso, ele pode atuar como catalisador básico e nucleofílico e os perfis cinéticos são similares para ambos os casos, onde há um aumento da constante de velocidade com o $\mathrm{pH}$, que aumenta conforme aumenta a quantidade da espécie neutra, reativa. Após atingir um pH onde a quantidade dessa espécie é máxima e invariável, o perfil cinético atinge um patamar $(\sim \mathrm{pH} 9)$. Normalmente observa-se que a constante de velocidade, no patamar, na catálise nucleofílica é maior que na básica e isso é esperado visto os processos nucleofílicos serem mais eficientes (rápidos). Já em valores de $\mathrm{pHs}$ abaixo do $\mathrm{p} K_{\mathrm{aH}}$ onde predomina o IMZ protonado, ele pode atuar apenas como catalisador ácido. Analogamente, o perfil cinético segue um comportamento com aumento da constante de velocidade com a diminuição do $\mathrm{pH}$, até atingir um patamar ( pH 5), onde temse a máxima quantidade formada da espécie protonada, reativada do IMZ. Ainda tem outra forma de atuação do IMZ, exemplificado para a RNAse na Figura 9, que envolve uma catálise bifuncional ácida-básica e o perfil cinético tem uma forma de sino. Isso porque a constante de velocidade é máxima onde se tem a máxima quantidade de espécies de IMZ protonado e neutro, que irão atuar concomitantemente na mesma etapa como catalisadores ácido e básico. Em valores de $\mathrm{pH}$ menor e maior que essa região ótima, a constante de velocidade diminui. Esse caso particular envolve dois grupos IMZ que estão ancorados em sítios diferentes (e.g RNAse e outros modelos abaixo) que tem uma sutil diferença em seu $\mathrm{p} K_{\mathrm{aH}}$. O perfil de sino é análogo para uma catálise bifuncional ácida-nucleofílica. ${ }^{11}$ Ainda, os perfis mostrados na Figura 13 são esperados tanto em reações inter- ou intramoleculares.

\section{Modelos intramoleculares}

Os modelos contendo o grupo IMZ que mimetizam particularidades enzimáticas podem estar baseados em uma arquitetura molecular simples ou mais complexa, como sistemas macromoleculares. O uso de moléculas químicas simples é uma forma eficiente de estudar separadamente as diferentes catálises promovidas pelas enzimas através de modelos intra- e intermoleculares. ${ }^{109}$ Neste contexto, destacam-se os modelos intramoleculares que possuem o grupo IMZ e fosforila/acila na mesma molécula, por exemplo o fosfato de 2-(2'-imidazolil)fenila (IMPP) e o fosfato de (bis(2-(1-metil-1H-imidazol-3-inio-2-il) fenila) (BMIPP) como modelos da RNAse, Figura 14. No caso do IMPP, o grupo IMZ protonado atua como catalisador ácido-geral na reação de hidrólise assistindo o grupo de saída, promovendo incrementos catalíticos de até $10^{6}$ vezes comparado com a hidrólise do análogo sem o grupo IMZ. De fato, o $\mathrm{p} K_{\mathrm{a}}$ do grupo de saída para IMPP é 7,85, significativamente menor que um fenol $\left(\mathrm{p} K_{\mathrm{a}} \sim 10\right)$, devido à eficiente transferência de próton pelo IMZ. Vale ressaltar que essa catálise ocorre apenas com a espécie protonada, presente em $\mathrm{pH}$ altamente ácido ( -2). ${ }^{114}$

Já para BMIPP, um mecanismo bifuncional bastante elegante foi proposto, onde sua hidrólise é $10^{11}$ vezes mais rápida que a hidrólise do fosfato de difenila. No entanto, ao comparar com um fosfato de diarila com grupo de saída de $\mathrm{p} K_{\mathrm{a}}$ similar ao BMIPP $(\sim 7,85)$, a catálise no BMIPP chega a $10^{7}$ vezes, muito impressionante para um modelo intramolecular. ${ }^{67}$ Estudos cinéticos para reação de hidrólise do BMIPP mostram um perfil de $\mathrm{pH}$ em forma de sino com reatividade máxima para a espécie bipolar (pH 6,5) apresentada na Figura 14. Inicialmente, o mecanismo proposto para BMIPP envolvia um grupo 

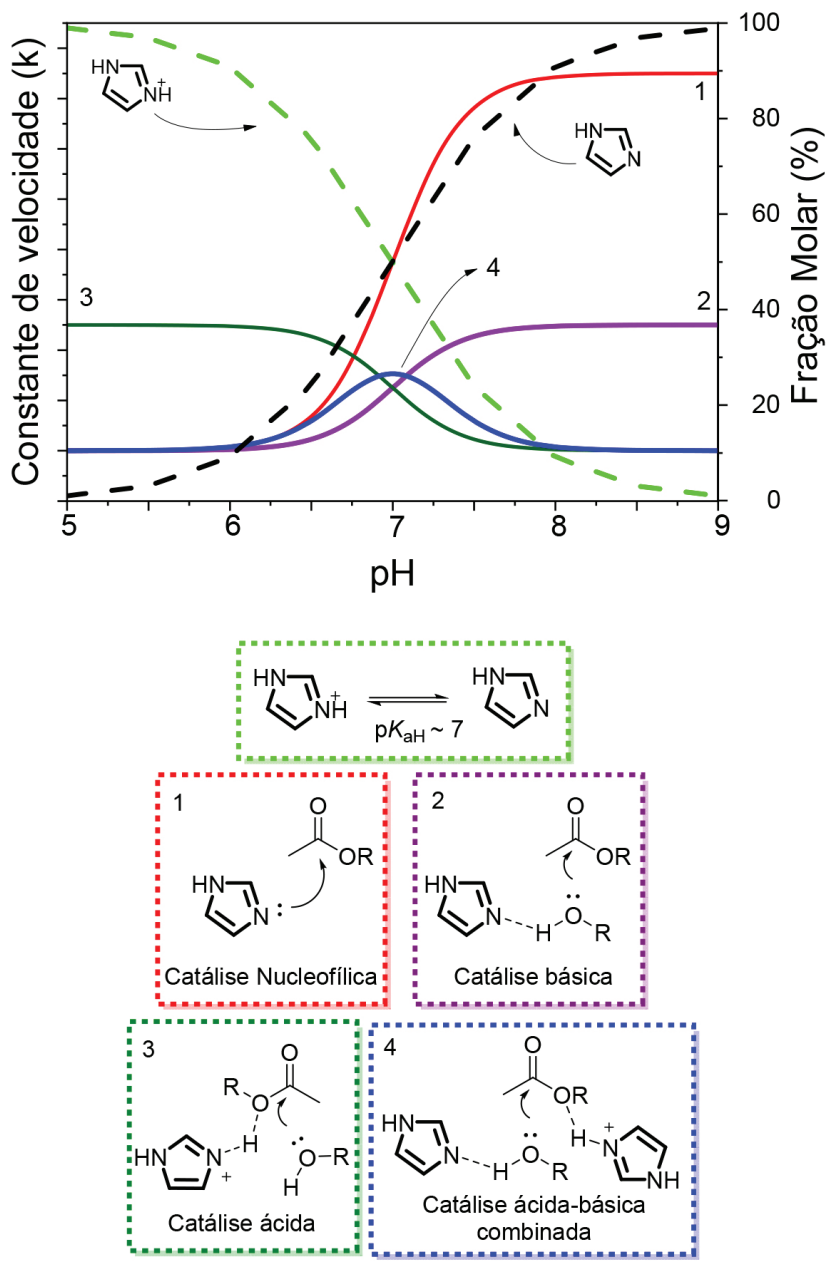

Figura 13. Perfis de pH cinéticos (previstos de acordo com equações típicas $)^{8,111-113}$ para reações com IMZ, catálise ácida, básica, bifuncional ácida-básica e nucleofílico. Está ilustrado também a fração molar das espécies neutra e catiônica do IMZ dependente do pH e mecanismos de catálise pelo IMZ
IMZ protonado e outro neutro promovendo simultaneamente catálise ácida e básica geral, respectivamente, tal como ocorre nas RNAse ${ }^{67}$ Todavia, novas evidências (espectrometria de massa de alta resolução e cálculos computacionais) apontam para um mecanismo bifuncional onde um grupo IMZ neutro atua como catalisador nucleofílico, enquanto outro IMZ protonado promove catálise ácida-geral, também recorrente em processos biológicos. ${ }^{115}$ Esse mecanismo leva a um intermediário cíclico instável que foi detectado por espectrometria de massas, e rapidamente se decompõe para um monóester de fosfato, análogo do IMPP. ${ }^{116}$ Ainda assim, uma catálise bifuncional ácidabásica-geral não pode ser totalmente descartada, podendo ainda ocorrer em alguma proporção.

A catálise nucleofílica intramolecular do IMZ também foi observada nos derivados de fosfato de $o$-(2'-imidazolil)naftila e (4-nitrofenila) (Figura 15), com incrementos catalíticos de $\sim 10^{7}$ vezes. Os intermediários cíclicos formados pelo ataque nucleofílico do IMZ foram detectados e se mostraram surpreendentemente estáveis. ${ }^{117}$ Outro modelo utilizado avaliou a reatividade dos fosforilimidazois através de reações de hidrólise onde através de calculos teóricos e técnicas experimentais se observou um estado de transição solto, devido a fraca ligação P-N amídica. ${ }^{18}$

A hidrólise de uma série de ésteres derivados do acetato de (imidazo-2-il) fenila (Figura 16) foi descrita, na qual o tipo de catálise intramolecular é determinado pela estrutura do éster devido a efeitos estéricos e eletrônicos. Assim, o grupo IMZ protonado atua como catalisador ácido-geral, assistindo a eliminação do grupo de saída, concomitante ao ataque da água no carbono do grupo da carbonila. Ainda, quando neutro, IMZ pode atuar como catalisador básicogeral auxiliando no ataque nucleofílico da água ou como nucleófilo, formando um intermediário tipo acetilimidazol, que rapidamente transfere o grupo acetila para água. Os incrementos catalíticos observados devido ao IMZ foram tipicamente $10^{4}$ vezes. ${ }^{19-121}$

A série de ésteres substituídos de 4-(2’-acetóxietil) imidazol, por sua vez, segue uma catálise intramolecular nucleofílica conforme ilustrado na Figura 17. Nesse caso, o perfil de pH indica que a espécie neutra é mais reativa e o intermediário tetraédrico é formado em um pré-equilíbrio. ${ }^{122}$

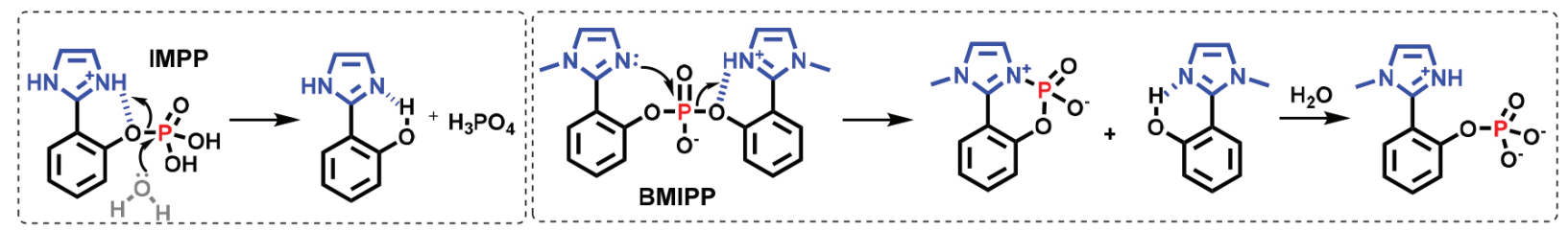

Figura 14. Mecanismos de catálise ácida e nucleofílica-ácida intramolecular como modelos de RNase ${ }^{114}$
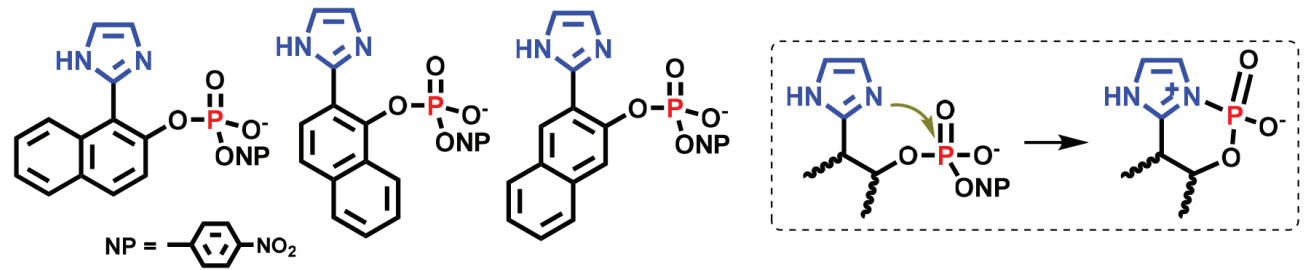

Figura 15. Modelos de catálise intramolecular baseados em IMZ ${ }^{117}$
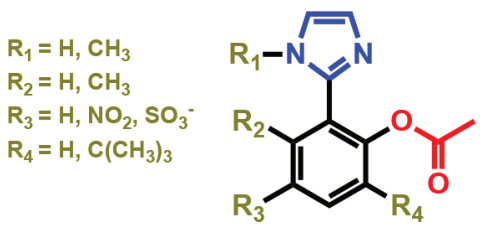

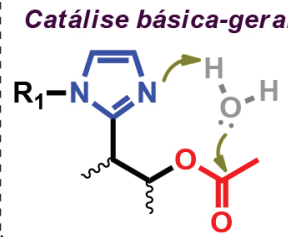

Catálise ácida-geral

Catálise nucleofilica

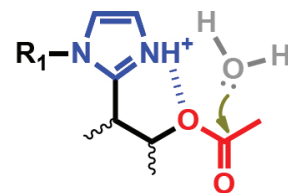

Figura 16. Modelos intramoleculares baseados em IMZ: catálise ácida, básica e nucleofílical ${ }^{119-121}$ 


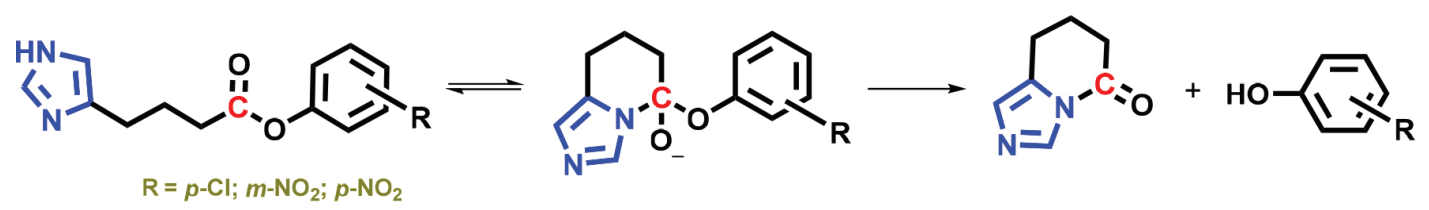

Figura 17. Mecanismo de reação intramolecular do 4-(2'acetoxietil)imidazol ${ }^{120}$

\section{Modelos intermoleculares}

Reações intermoleculares com derivados de IMZ também são importantes para modelar sítios enzimáticos e projetar catalisadores, promissores no design de enzimas artificiais. Além disso, muitas vezes essas moléculas pequenas podem ser utilizadas por si só como organocatalisadores, sendo muitas vezes compatíveis com meio aquoso, mais simples, facilmente obtidas e mais baratas que sistemas mais complexos. ${ }^{123}$ Em sistemas intermoleculares, as variações nas estruturas do derivado de IMZ (i.e. mudança nos substituintes) são mais simples de serem feitas do ponto de vista da síntese orgânica. Dessa forma, permitindo a execução de estudos mais profundos e com maior extensão, que após consolidados podem ser estrategicamente projetadas em sistemas intramoleculares.

Muitas reações apenas com IMZ já foram investigadas e segue na Tabela 1 um resumo de algumas reações de desfosforilação e desacilação. Podemos observar que na maioria dos casos apresentados na Tabela 1 as reações ocorrem a partir de um mecanismo nucleofílico, relacionado aos grupos abandonadores com baixos valores de $\mathrm{p} K_{\mathrm{a}}$ onde o $p$-nitrofenol e 2,4 dinitrofenol tem $\mathrm{p} K_{\mathrm{a}}$ de 7,1 e 4,1, respectivamente: fosfato de dietila e 2,4-dinitrofenila (DEDNPP), fosfato de etila e 2,4-dinitrofenila (EDNPP), fosfato de bis(2,4-dinitrofenila) (BDNPP), Paraoxon, fosfato de $p$-nitrofenila (pNPP), fosfato de ciclo-1,3 propila 2,4-dinitrofenila (CDNPP), trifosfato de adenosina (ATP), acetato de fenila (ACF), acetato de p-nitrofenila (APNF) e acetato de 2,4-dinitrofenila (ACDNF). Por outro lado podemos observar que para o caso de ésteres de acilas como acetato de $p$-metoxifenila (ACMOF) e acetato de $p$-metilfenila (ACMF), que possuem grupos abandonadores com valores de $\mathrm{p} K_{\mathrm{a}}$ mais elevados ( $\mathrm{p} K_{\mathrm{a}} 10,41$ e 10,26 para $p$-metoxifenol e $p$-metilfenol, respectivamente), ${ }^{124,125}$ o mecanismo sofre um deslocamento para o de catálise básica geral onde o IMZ não é reativo o suficiente para atacar e remover o grupo fenólico diretamente. Dessa forma, o IMZ auxilia o ataque de outro nucleófilo, como a água, a partir da abstração de um próton. ${ }^{126,127}$ Ainda podemos observar na Tabela 1 que os incrementos catalíticos das reações com o IMZ são dependentes das estruturas dos eletrófilos estudados, mas que em todos os casos esses incrementos são bastante altos, evidenciando a eficiência da reação catalisada.

Um mecanismo geral para as reações de desfosforilação e desacilação catalisada nucleofilicamente pelo IMZ está representado na Figura 18, ${ }^{52,128-130} \mathrm{em}$ que inicialmente o IMZ ataca o átomo de fósforo levando a um intermediário fosforilado. Esse intermediário é rapidamente hidrolisado devido a instável ligação entre o fósforo e o nitrogênio imínico. Para as reações com ésteres carboxílicos o mecanismo é semelhante, com a formação de um intermediário acetilIMZ. ${ }^{135}$ Ele tem sido amplamente avaliado buscando compreender a transferência do grupo acila. ${ }^{136-138}$ A detecção dos intermediários de IMZ fosforilados e acilados fundamentam os estudos de mecanismos dessas reações. Além disso, auxiliam na compreensão de processos biológicos e no caso dos fosforilimidazois existe o potencial desenvolvimento de moléculas biosinalizadoras com fins terapêuticos. ${ }^{128}$

Para as reações nucleofílicas de desacilação, diversos derivados de IMZ foram estudados e se observou que o aumento da basicidade do catalisador nucleofílico aumenta sua reatividade, exceto em casos de impedimento estérico, conforme previsto pelo gráfico linear de Bronsted para $\log k_{\mathrm{N}}$ vs $\mathrm{p} K_{\mathrm{a}}{ }^{\mathrm{Nu}} .{ }^{126,139} \mathrm{O}$ mesmo comportamento linear
Tabela 1. Resumo de reações intermoleculares com IMZ

Reação

ancremento catalítico está apresentado como a razão entre a constante de segunda ordem $\left(\mathrm{L} \mathrm{mol}^{-1} \mathrm{~s}^{-1}\right)$ da reação nucleofílica e a constante correspondente da reação espontânea, considerando a concentração da água $\left(55,5 \mathrm{~mol} \mathrm{~L}^{-1}\right)$.

também já foi observado em reações de desfosforilação, sendo avaliadas uma gama menor de derivados de IMZ (vide infra).

Surpreendentemente, na reação com ésteres tiofosfóricos Paratína etílica (EPT) e metílica (MPT), o IMZ ataca nucleofilicamente os carbonos alifáticos, sendo obtidos como produtos IMZ $N$-alquilados (Figura 19) com incrementos de $7 \times 10^{3}$ e $1 \times 10^{5}$ para as reações com o EPT e MPT, respectivamente, mostrando que o IMZ cliva os mesmos com eficiência, apesar de não ser um processo catalítico. ${ }^{140,141}$ Esse resultado evidencia o potencial de agente alquilante desses pesticidas, podendo essa reação ser utilizada para síntese de alquilimidazois em condições brandas de $\mathrm{pH}$ e solvente aquoso. Esse comportamento é pouco observado em reações com IMZ, onde espera-se que o mesmo 

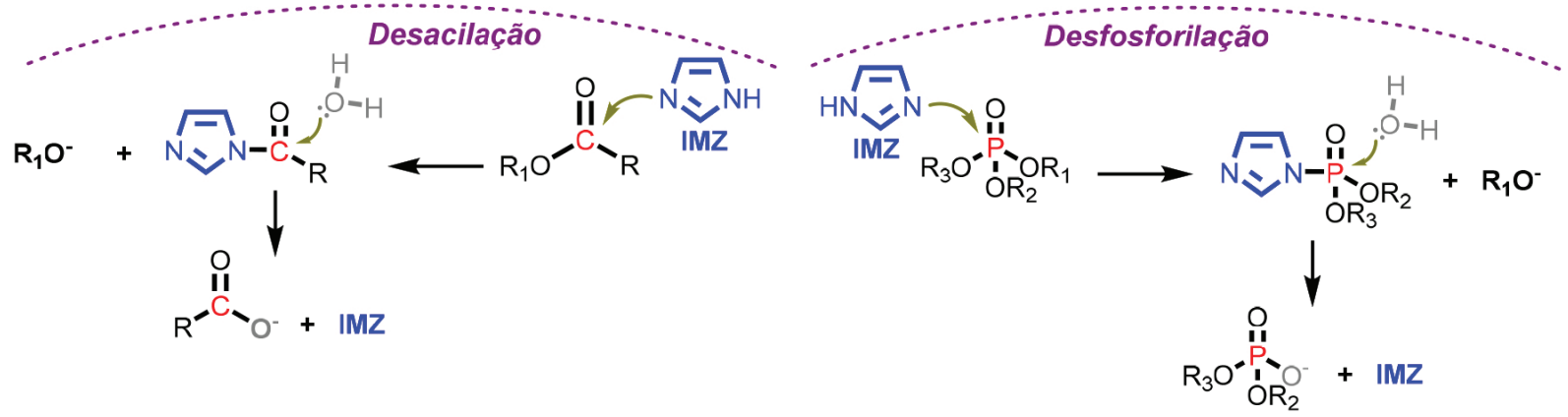

Figura 18. Esquema geral de reações de desacilação e desfosforilação nucleofílicas promovidas pelo IMZ ${ }^{52,128-130}$

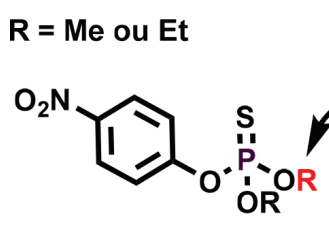

MPT ou EPT

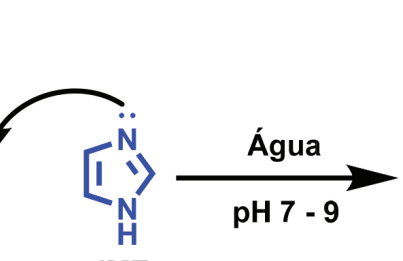

IMZ
Imidazol alquilado

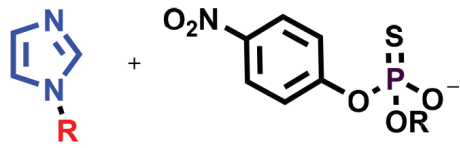

Figura 19. Reação entre o IMZ e MPT e EPT $T^{140,141}$

ataque o átomo de fósforo. Entretanto, comportamento similar já havia sido observado para o 1-MEI em solvente orgânico. ${ }^{142}$

Existem também reações intermoleculares que se beneficiam de catálise intramolecular, por exemplo, os derivados de 2-imidazol, 4,5-difenilimidazol e benzimidazol substituídos com grupo de ácido carboxílico (Figura 20A). Esses compostos foram estudados na reação de desacilação do APNF, que apresentou uma catálise intramolecular básica-geral pelo grupo vizinho carboxilato no IMZ, aumentando sua nucleofilicidade. Ainda que com discretos incrementos de até 3 vezes, esses modelos intramoleculares utilizados em reações intermoleculares são interessantes modelos do sítio ativo da quimotripsina. ${ }^{143} \mathrm{Um}$ derivado de IMZ estruturalmente mais simples, o ácido (4-imidazoil)-acético (4-AEZ) (Figura 20B) quando utilizado como catalisador em reações de desfosforilação do BDNPP e fosfato de bis(4-nitrofenila) (BNPP) apresentou incrementos de $10^{4}$ e $10^{5}$ vezes em relação a hidrólise espontânea e 4,6 vezes em relação ao IMZ. Nesse caso, também foram observados efeitos de catálise básica intramolecular combinada com catálise nucleofílica, sendo esses os responsáveis pela atividade catalítica. ${ }^{144}$ Por outro lado o mesmo derivado de IMZ (4-AEZ) quando avaliado como catalisador em reações de desacilação do acetato de $p$-toluila (APT), apresentou uma atividade catalítica menor que o próprio IMZ, fato inesperado devido a maior basicidade do 4-AEZ em relação ao IMZ. ${ }^{145}$ Nesse caso, nenhum efeito de catálise intramolecular foi observado, evidenciando que a atividade catalítica apresenta dependência em relação ao substrato.

Outras formas de catálise cooperativa são os derivados de IMZ bifuncionais, isso é, aqueles que podem combinar dois sítios ativos. Reações de desacilação do APNF com derivados de IMZ combinados com ácido hidroxâmico (conhecidos como potentes nucleófilos) foram estudadas a fim de compreender efeitos de uma catálise cooperativa (Figura 21). ${ }^{146}$ Quando o grupamento R escolhido foi metila, o intermediário de reação acilado foi atacado e clivado pelo anel de IMZ vizinho. Entretanto, apesar de uma molécula pequena ser capaz de promover uma reação de catálise bifuncional os valores de constante velocidade para a etapa de regeneração do catalisador não

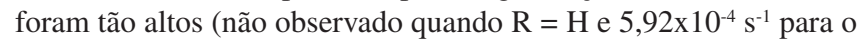
quando $\mathrm{R}=\mathrm{Me}$ ) como esperado pelos autores do estudo.

\section{O efeito de substituintes em imidazóis}

Como discutido anteriormente, os substituintes presentes no IMZ modificam algumas das características físicas e químicas desses
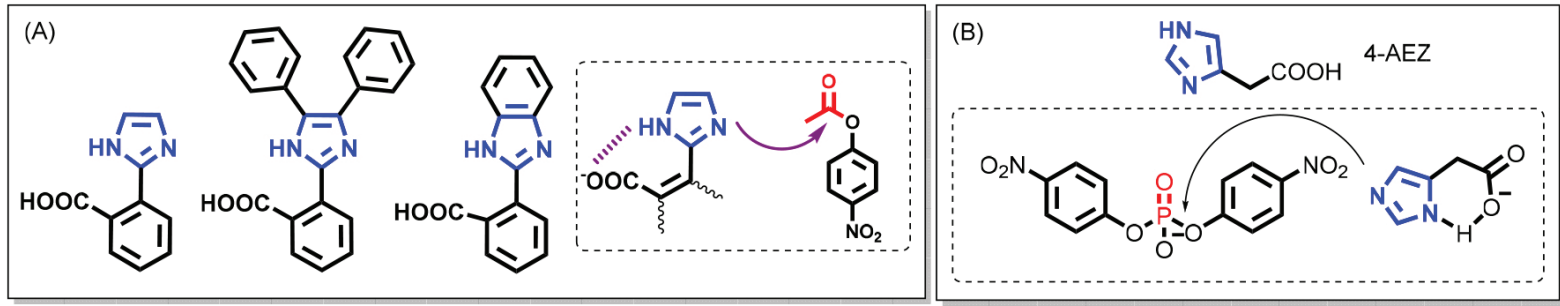

Figura 20. Catálise básica intramolecular combinada com catálise nucleofílica em reações de desacilação e desfosforilaçãa ${ }^{143,144}$

\section{$\mathrm{R}=\mathrm{H}$ ou Me}<smiles>[R]N(OOCCCC(=O)Oc1ccc([N+](=O)[O-])cc1)C(=O)c1cnc[nH]1</smiles>

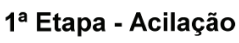

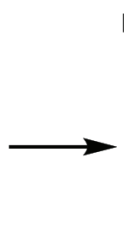

$2^{\mathrm{a}}$ Etapa - Ataque intramolecular; Regeneração do catalisador

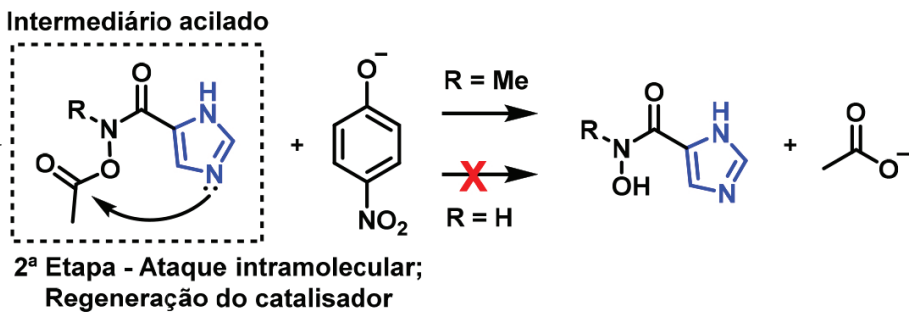

Figura 21. Catálise bifuncional em derivados de $I M Z^{146}$ 
compostos. Um dos parâmetros termodinâmicos que mais afetam a reatividade dos derivados IMZ substituídos é o $\mathrm{p} K_{\mathrm{aH}}$, uma vez que a basicidade está ligada intimamente a atividade catalítica nucleofílica e ácida-básica. Em um estudo anterior, Komyama mostrou que para a reação de desfosforilação do BDNPP, a reatividade de uma série de derivados de IMZ tem uma relação linear com $\mathrm{p} K_{\mathrm{aH}}$ (Gráfico de Bronsted; Figura 22), exceto para o 4-AEZ (Figura 22), que apresenta combinação de catálise básica e nucleofílica (vide supra, Figura 20). ${ }^{144}$

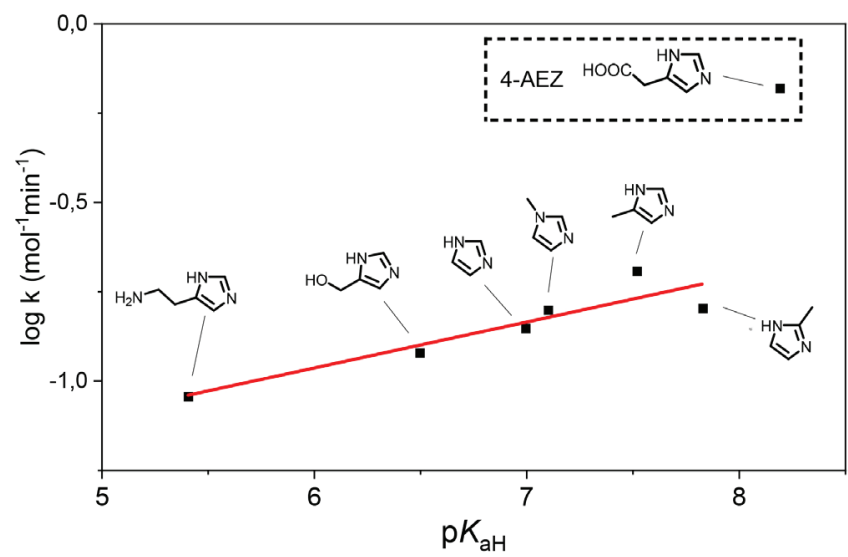

Figura 22. Gráfico de Bronsted para reação de desfosforilação do BDNPP com uma série de derivados de IMZ ${ }^{144}$

Em outro estudo de Schmir e Bruice, uma gama ainda maior de derivados de IMZ foi avaliada, desta vez em reações de desacilação do APNF. ${ }^{147}$ Foi verificado que o 4-nitroimidazol $\left(\mathrm{p} K_{\mathrm{aH}}=1,7\right)$ é mais reativo que o IMZ $\left(\mathrm{p} K_{\mathrm{aH}}=6,95\right) \mathrm{em} \mathrm{pH}=8$. Esse fato é explicado pelo aparecimento da espécie aniônica do 4-nitroimidazol $\left(\mathrm{p} K_{\mathrm{a}}=9,1\right)$, ou seja, o substituinte $-\mathrm{NO}_{2}$ torna o nitrogênio do tipo piridina uma base fraquíssima, mas por outro lado, aumenta a acidez do hidrogênio do tipo pirrol em 5,42 unidades de $\mathrm{p} K_{\mathrm{a}}$ em relação ao IMZ sem substituições, sendo então a espécie aniônica responsável pela atividade catalítica. Interessantemente os autores também verificaram que o $\mathrm{p} K_{\mathrm{aH}}$ dos derivados de IMZ é linearmente relacionado com $\mathrm{p} K_{\mathrm{a}}$ das mesmas espécies (Figura 23).

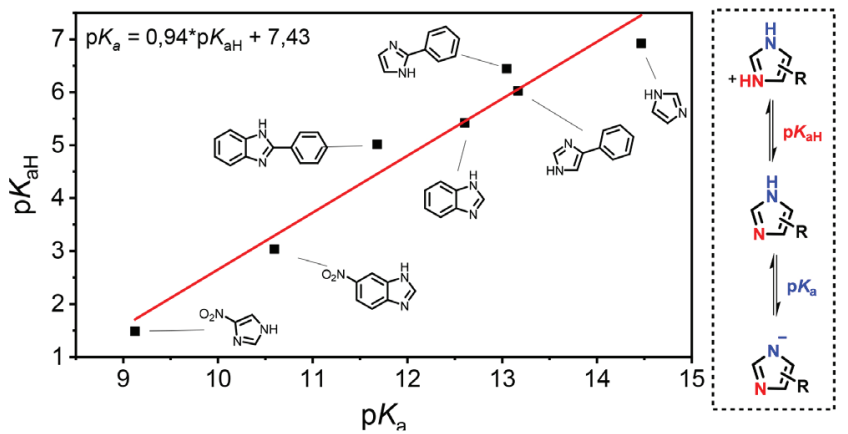

Figura 23. Relação linear entre a acidez do nitrogênio do tipo pirrol e tipo piridina $\left(p K_{a H}\right.$ versus $p K_{a}$ ) para alguns derivados de IMZ $Z^{147}$

Assim, como a reatividade dos derivados de IMZ para o APNF é governado pela basicidade (i.e. $\mathrm{p} K_{\mathrm{aH}}$ e $\mathrm{p} K_{\mathrm{a}}$ r relação de Bronsted linear) os autores deduziram uma equação para prever as constantes de velocidade de acordo com os valores de $\mathrm{p} K_{\mathrm{a}}$ e $\mathrm{p} K_{\mathrm{aH}}$ para cada derivado de IMZ. A Figura 24 apresenta os dados experimentais para uma série de derivados de IMZ, na reação de desacilação, em que é possível observar que a equação prevista segue a tendência dos dados experimentais para os derivados substituídos nas posições 4 e 5 do anel. Entretanto, quando são avaliados derivados substituídos na posição 2 do anel, os dados experimentais desviam do esperado quando considerados apenas os respectivos valores de $\mathrm{p} K_{\mathrm{aH}}$, evidenciando que o fator estérico tem importância crucial na diminuição da reatividade. ${ }^{147}$

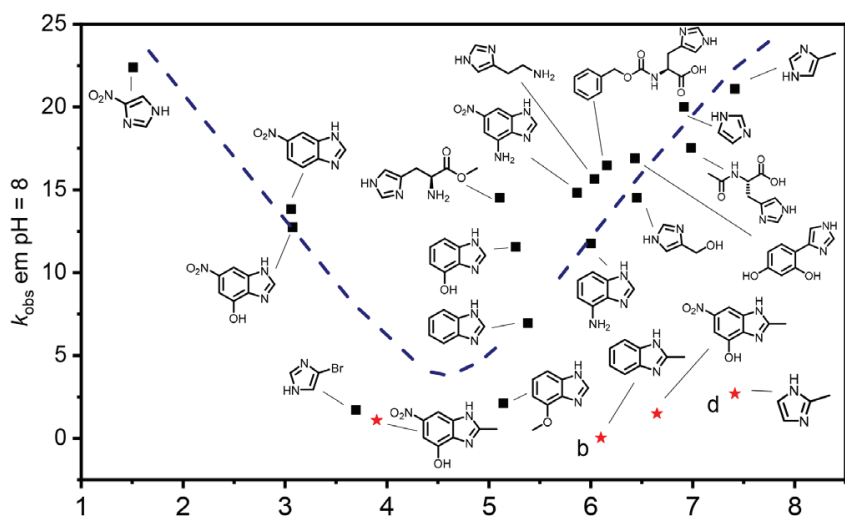

Figura 24. Gráfico de $k_{o b s}$ versus $p K_{a H}$ para derivados de IMZ 4(5) substituídos (quadrados) e 2 substituídos (estrelas) para reação de desacilação do APNF, conjuntamente com o ajuste teórico (linha tracejada) para os dados experimentais $^{147}$

Nesses estudos, a diferença de reatividade entre diferentes tautômeros do IMZ da posição 4(5) não pôde ser observada devido a dificuldades experimentais. Mais recentemente acessado por técnicas avançadas de RMN e cálculos teóricos, a reatividade do par tautomérico 4(5) MEI frente à reação de desfosforilação do DEDNPP pôde ser avaliada separadamente. $\mathrm{O}$ estudo mostrou que apesar da população apresentar a proporção 4:6 para 5-MEI:4-MEI, o tautômero da posição 5 é 31 vezes mais reativo que o da posição 4 . Isso demonstra que para essa reação é, na verdade, o 5-MEI o responsável pela alta reatividade com o 4-MEI tendo reatividade comparável ao do 2-metilimidazol (2-MEI) (o menos reativo entre os estudados). ${ }^{148}$

Outro questionamento relacionado à reatividade dos derivados de IMZ diz respeito ao efeito esperado quando o mesmo é alquilado com grandes cadeias alifáticas, uma vez que essas, entre si, não alteram de forma significativa o $\mathrm{p} K_{\mathrm{aH}}$. Knowles e Blyth estudaram as reações de imidazóis $N$-alquilados ( $N$-decil, $N$-octil, $N$-hexil, $N$-butil e $N$-etil imidazol) com ésteres de $p$-nitrofenila de cadeia longa e curta (decanoato, octanoato, hexanoato, butanoato de $p$-nitrofenila e APNF) (Figura 25) buscando compreender o efeito de interações hidrofóbicas na reação de desacilação. ${ }^{149}$ Os derivados de IMZ alquilados estudados nesse trabalho apresentaram $\mathrm{p} K_{\mathrm{aH}}$ próximo de 7,1 e, como esperado, praticamente não apresentaram diferença nas constantes de velocidade quando reagidos com os ésteres de cadeia curta com 2 e 4 carbonos (i.e. a cadeia alifática não contribuiu de forma significante na reatividade do derivado de IMZ). Entretanto, foi observado que os ésteres de cadeia longa reagem mais rápido com os IMZ de cadeia longa (i.e. decilimidazol com decanoato de $p$-nitrofenila), bem como os IMZ de cadeia curta reagem mais
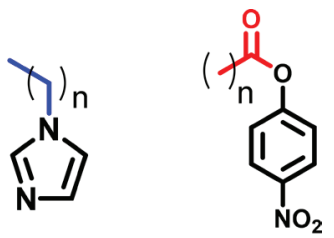

$\mathrm{n}=1,3,5,7$ e 9

Figura 25. Influência de grupamentos alquílicos na reatividade de derivados de IMZ N-alquilados nas reações de desacilação de ésteres de cadeia longa e curta $^{149}$ 
vagarosamente com os ésteres de cadeia longa (i.e. decilimidazol com APNF). Ou seja, a interação entre as cadeias alifáticas altera de forma significante a reatividade, com os ésteres de cadeia longa sendo os mais afetados pelas mudanças estruturais. Dessa forma a projeção de catalisadores derivados de IMZ em outros ambientes como polimérico e micelares são promissores e podem moldar a reatividade dos pares nucleófilo-eletrófilo.

Moléculas derivadas de IMZ também vêm sendo amplamente estudadas, inclusive com moléculas biológicas como RNA que possuem grupos fosforilas. O derivado tris (aminobenzilimidazol) (Figura 26A) clivou efetivamente substratos de RNA com tempo de meia-vida de 120 min. Comparado com a reação espontânea ( $t_{1 / 2}=13,4$ anos), os incrementos catalíticos chegam a $10^{4}$ vezes. ${ }^{150}$ Outras moléculas menores de IMZ também se mostraram capazes de clivar o RNA, como conjugados de espermina-IMZ ${ }^{151}$ e oligonucleotídeos conjugados com IMZ ${ }^{152}$ e de uridina-IMZ. ${ }^{153}$ Recentemente um derivado de IMZ funcionalizado com o aminoácido serina e uma cadeia lateral alifática de 14 carbonos (Figura 26B) foi capaz de mimetizar o mecanismo de catálise enzimática, e quando combinado com surfactantes apresentou incrementos catalíticos na ordem $1,6 \times 10^{5}$ para a reação de hidrólise do benzoato de $p$-nitrofenila. ${ }^{154}$

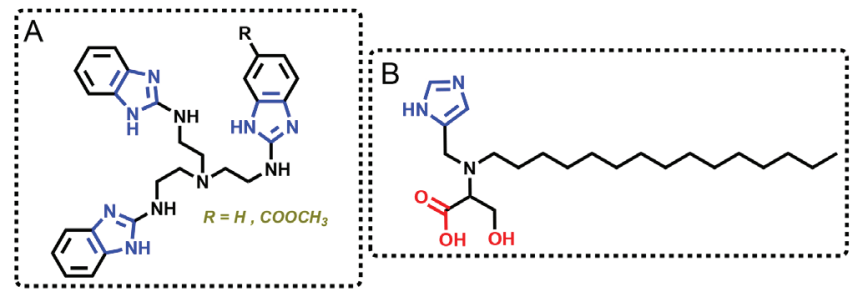

Figura 26. Derivados de IMZ (A) (tris aminobenzil imidazol) e (B) (4(5) (aminometil)(N-pentadecil serino)imidazol capazes de agir como enzimas artificiais $^{150,154}$

Além das variações estruturais que modificam a reatividade dos derivados de IMZ, a troca de solventes também é capaz de interferir na reatividade. Em reações do IMZ com o APNF em meios ricos em acetonitrila ocorrem mudanças na cinética de reação onde há uma dependência mista de primeira e segunda ordem entre o $k_{\text {obs }}$ e a concentração do IMZ, indicando que a reação ocorre por dois caminhos de forma concomitante. No primeiro, o IMZ atua como catalisador básico-geral e o segundo ocorre com a participação de duas moléculas de IMZ, uma agindo como nucleófilo e outra como catalisador básico geral. ${ }^{155}$ Além disso, a mudança de água para acetonitrila modificou a etapa determinante de velocidade, do ataque nucleofílico do IMZ sobre a carbonila do éster para o colapso do intermediário tetraédrico, uma vez que o $p$-nitrofenol tem um $\mathrm{p} K_{\mathrm{a}}$ muito mais elevado nesse meio $\left(\mathrm{p} K_{\mathrm{a}}=21\right)$, o que torna dificultada sua saída em relação ao IMZ ( $\left.K_{\mathrm{aH}} 14\right)$. Em meio aquoso, tanto o IMZ como o $p$-nitrofenol tem praticamente a mesma basicidade. O mesmo tipo de reatividade foi observado quando os substratos estudados foram o cloroacetato e dicloroacetato de $p$-nitrofenila. ${ }^{156}$ Em um estudo de hidrólise da $p$-nitrotrifluoroacetanilida, catalisada pelo IMZ, variando a composição de água-acetonitrila os autores observaram um mecanismo de catálise básica geral pelo IMZ, e um comportamento bastante interessante no perfil de constante de velocidade versus concentração de água onde o mesmo se dividiu em três regiões. As duas primeiras lineares (com coeficientes angulares diferentes) entre 0 - 1 e $1-10 \mathrm{~mol} \mathrm{~L}^{-1}$ e uma terceira região quadrática acima de $10 \mathrm{~mol} \mathrm{~L}^{-1}$. Os autores atribuem esse comportamento a efeitos de solvatação, transferência de próton no estado de transição e concentração de nucleófilo uma vez que a água faz esse papel e o IMZ atua como catalisador básico geral. ${ }^{157,158}$
Reações do IMZ com o organofosforado fosfinato de 2,4-dinitrofenila e difenila foram avaliadas em acetonitrila com baixa concentração de água $\left(1 \mathrm{~mol} \mathrm{~L}^{-1}\right)$ nesse caso apresentando mecanismo de catálise nucleofílica clássica, entretanto, para o análogo fosfinato de 4-nitrofenila e difenila, nas mesmas condições, o IMZ não apresentou reatividade apreciável. ${ }^{159}$ Em reações do organofosforado DEDNPP com IMZ e 1-MEI em misturas DMSO-água, o IMZ foi mais efetivo que o 1-MEI em todas as condições e a partir de misturas $30 \%$ DMSO o meio foi capaz de tornar as reações de desfosforilação mais efetivas (incrementos de $10^{3}$ e $0,5 \times 10^{3}$ para o IMZ e 1 -MEI, respectivamente, em $100 \%$ DMSO). ${ }^{160}$ Ainda, o efeito do meio foi avaliado segundo a escala de Catalán, ${ }^{161}$ que leva em consideração a acidez, basicidade e polarizabilidade do meio, indicando que as ligações de hidrogênio solvente-reagentes tem papel crucial na reatividade dos derivados de IMZ. ${ }^{160}$

\section{Catalisadores macro- $e$ nanoestruturados}

Outra classe importante de modelos intermoleculares envolvem moléculas com arquitetura mais complexa como derivados de macroe nanoestruturas, muitas vezes denominadas enzimas artificiais ou "synzymes", pois conseguem mimetizar aspectos multifuncionais e geométricos das enzimas naturais. ${ }^{162}$ Isso porque a estrutura complexa desses materiais permite ancorar vários grupos reativos que atuam em sinergismo com algumas funcionalidades intrínsecas desses materiais, como características hidrofóbicas que podem atrair reagentes para sua proximidade. ${ }^{163} \mathrm{O}$ termo "synzyme" foi primeiro empregado por Klotz, I. M. e colaboradores ${ }^{164}$ para uma classe de polímeros com grupos IMZ e dodecil ancorados na cadeia da polietilenoimina que foram estudados na reação dos ésteres de nitrofenila. O polímero catalítico obtido mostrou eficiência catalítica 270 vezes maior a respectiva reação apenas com IMZ, atribuída aos efeitos atrativos da cadeia polimérica pelo éster (caproato de $p$-nitrofenila) por interações hidrofóbicas. ${ }^{165}$

Desde então, muitas enzimas artificias derivadas de IMZ vem sendo estudadas, destacando-se as poliméricas. ${ }^{162}$ Os polímeros apresentam propriedades que podem ser moduladas buscando otimizar aspectos conformacionais e catalíticos, por exemplo o peso molecular, a polidispersidade, a hidrofobicidade e grau de "crosslinking". ${ }^{166,167} \mathrm{O}$ potencial catalítico desses polímeros vem sendo avaliado com moléculas biológicas como RNA, onde, por exemplo, poliaminas com grupos IMZ ancorados se mostraram seletivos na quebra do RNA, desejável para terapia genética. Apenas o IMZ leva a uma clivagem não seletiva em reação análoga. ${ }^{168}$

Um dos polímeros derivados de IMZ que apresenta uma atividade catalítica bastante interessante é o poli $N$-vinil(imidazol) (PVI) (Figura 27), formado a partir da polimerização do 1-vinil(imidazol), sendo bastante explorado na literatura. ${ }^{169,170}$ A proximidade dos grupos imínicos (Figura 27) altera os equilíbrios ácido-base, com o PVI apresentando capacidade tamponante em uma longa faixa (2-9), muito maior que a do IMZ sozinho (6-8). ${ }^{169}$ Quando testado em reações de desfosforilação os incrementos catalíticos são bastante altos, na faixa de $10^{5}$ e $10^{7}$ vezes para o DEDNPP e BDNPP em comparação a hidrólise espontânea. Além disso, a investigação do mecanismo de reação mostrou que com o DEDNPP a reação se procede via o clássico ataque nucleofílico do nitrogênio imínico sobre o átomo de fósforo. Para a reação com o BDNPP, devido a menor reatividade do diésteres de fosfato, o mecanismo é deslocado para uma catálise bifuncional, com a participação de um monômero protonado e outro neutro onde uma molécula de IMZ atua como nucleófilo e outra ativando o grupo fosforila a partir de catálise ácida. ${ }^{169}$

Para além de reações de desfosforilação, a capacidade de transferência do grupo acila e fosforila pelos derivados de IMZ pode ser utilizada no sentido de promover reações de acetilação 


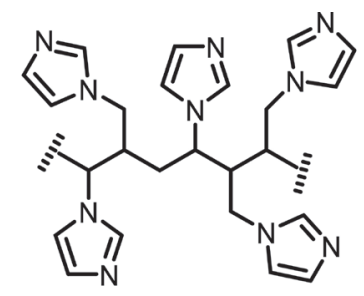

Estrutura do PVI

Figura 27. Estrutura reduzida do $P V I^{169}$

de álcoois, aminas, tióis, etc. Em um trabalho recente, o PVI se mostrou extremamente eficiente em reações de acetilação com baixos tempos de reação (5 minutos), ausência de solvente, e vários ciclos de reutilização com pequenas perdas de atividade catalítica (2\%). ${ }^{170}$

Copolímeros de vinil imidazol e ácido hidroxâmico já tiveram sua capacidade catalítica explorada em reações de desacilação. Kunitake e Okahata descreveram a atividade catalítica combinada do copolímero em reações de desacilação com ésteres de cadeia longa e cadeia curta. Foi proposto o efeito cooperativo entre os sítios IMZ e ácido hidroxâmico, com o IMZ atuando como catalisador básico geral. Nesse caso o IMZ, em sua forma neutra, auxilia o ataque nucleofílico do grupo hidroxâmico a partir da abstração do próton do grupo - $\mathrm{OH}$ (Figura 28). O copolímero de IMZ com ácido hidroxâmico foi de 5 a 30 vezes mais eficiente que os polímeros contendo esses mesmos grupos individualmente..$^{171}$

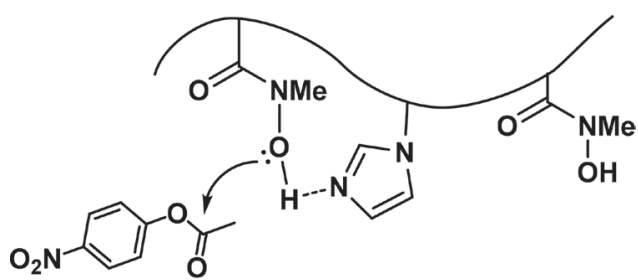

Figura 28. Mecanismo de ataque do catalisador polimérico baseado em IMZ e grupos ácido hidroxâmico na reação com o $A P N F^{171}$

Outro polímero que teve a atividade catalítica avaliada foi o ácido poliacrílico funcionalizado com grupos IMZ (PAIM). O PAIM apresentou proporção 1:1 de IMZ e ácidos carboxílicos ${ }^{172}$ e se mostrou bastante eficiente em reações de desfosforilação e desacilação de ésteres ativados, com incrementos catalíticos na ordem de $7 \times 10^{5}$ vezes para o DEDNPP. Ainda quando combinados com o surfactante CTAB, o incremento catalítico do polímero foi ainda maior, na ordem de $10^{6}$ vezes em relação a hidrólise espontânea, atribuída a formação de agregados supramoleculares que seriam capazes de formar bolsões hidrofílicos que acomodariam o substrato DEDNPP, facilitando a reação. ${ }^{173}$ Recentemente Nothling e colaboradores descreveram a síntese de uma catalisador, na qual foram ancorados na resina de Merrifield uma molécula contendo os grupos hidroxila, ácido carboxílico e IMZ próximos, com intuito de mimetizar as esterases. Nesse caso, foi mostrado que os três grupos são importantes para a aumentar a velocidade da reação com o substrato escolhido butirato de $p$-nitrofenila e que a retirada de qualquer desses grupos diminui a atividade catalítica. ${ }^{174}$ Outros sistemas poliméricos combinados com o IMZ, utilizados como catalisadores estão descritos na literatura e evidenciam a ampla potencialidade dessa combinação como em polímeros de acrilamida, ${ }^{175}$ copolímeros de vinilimidazol, ${ }^{176}$ poli 4(5) vinilimidazol, ${ }^{177}$ poliestireno, ${ }^{178} \mathrm{e}$ ácido acrílico. ${ }^{179}$

Outro suporte interessante para enzimas artificiais são as ciclodextrinas. Breslow e colaboradores, ${ }^{163,180}$ propuseram um modelo de RNase ancorando grupos IMZ na $\beta$-ciclodextrina levando a ciclodextrina-bis(imidazol) que foi extensivamente estudada na reação de hidrólise do fosfato de 4-terc-butilcatecol, Figura 29. Resultados indicam um elegante mecanismo de catálise bifuncional ácida-básica geral pelos grupos IMZ, tal ilustrado na Figura 29, com incrementos catalíticos de 120 vezes. ${ }^{181}$ A dependência da reação com a posição dos grupos IMZ na ciclodextrina está de acordo com um mecanismo onde um grupo IMZ desprotonado atua como base-geral, auxiliando no ataque nucleofílico da água no éster, enquanto outro grupo IMZ protonado atua como ácido-geral amparando a clivagem do éster cíclico. Ainda, observou-se uma alta seletividade (> 99:1) para o isômero A (Figura 29), em comparação com a hidrólise básica que leva a uma mistura dos dois produtos. ${ }^{182}$

Outra classe interessante de modelos macromoleculares são os dendrímeros que possuem ramificações simétricas de unidades menores e caracterizam-se por apresentar uma região hidrofóbica (interna) e hidrofílica (superficial). Ainda, os dendrímeros são particularmente promissores devido a sua maior monodispersidade comparada aos polímeros, ideal no design de enzimas artificiais, pois as enzimas biológicas são monodispersas, i.e. possuem unidades moleculares uniformes em termos de massas moleculares. Um estudo mostrou que o dendrímero com grupos histidina mostrado na Figura 30 atua como catalisador na reação de hidrólise de 8-butiloxipireno1,3,6-trisulfonatos, com incrementos catalíticos de $9 \times 10^{4}$ vezes. Sua forma de atuação foi atribuída a fatores hidrofóbicos, e ao grupo IMZ que pode atuar como nucleófilo ou catalisador básico-geral. ${ }^{183}$

Diversos materiais derivados de biopolímeros, resíduos agrícolas e nanomateriais de carbono vem sendo utilizados como suportes para obter catalisadores derivados de IMZ, que tem mostrado efeitos sinérgicos. ${ }^{184-187}$ Uma das abordagens é a funcionalização covalente pois garante que os grupos reativos permaneçam no suporte após vários ciclos e não lixiviem facilmente. A funcionalização desses materiais se baseia na formação de ligações amida, partindo do derivado de IMZ 1-amino-3-propilimidazol e dos grupos ácidos carboxílicos presentes no material de interesse, através da ativação da carboxila com reagentes etilenocarbodiimida (EDC) e $N$-hidroxisuccinimida (NHS) (Figura 31). ${ }^{188}$ Para esses compósitos, quando considerados apenas a quantidade de grupos IMZ, eles se mostraram muito superiores que o IMZ livre, evidenciando a potencialidade e sinergia desses materiais para aplicações em catálise. Materiais como o óxido de grafeno (GO) na forma de pó e de filmes finos apresentaram interessante atividade catalítica frente a reações de desfosforilação, reduzindo o tempo de meia vida do pesticida Paraoxon de mais de 516 anos para apenas 1 mês no caso do compósito na forma de pó e para 13 dias para o compósito na forma
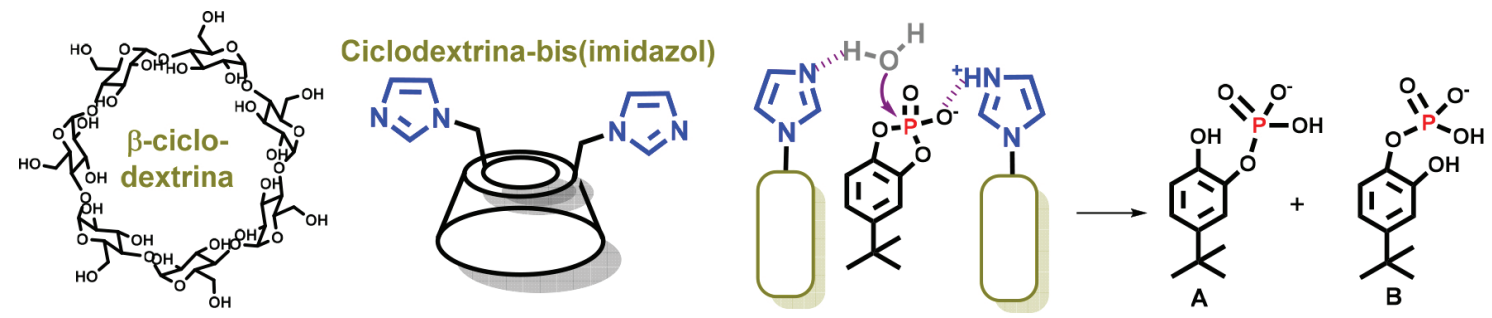

Figura 29. Catalisador baseado em IMZ e ciclodextrina ${ }^{181,182}$ 


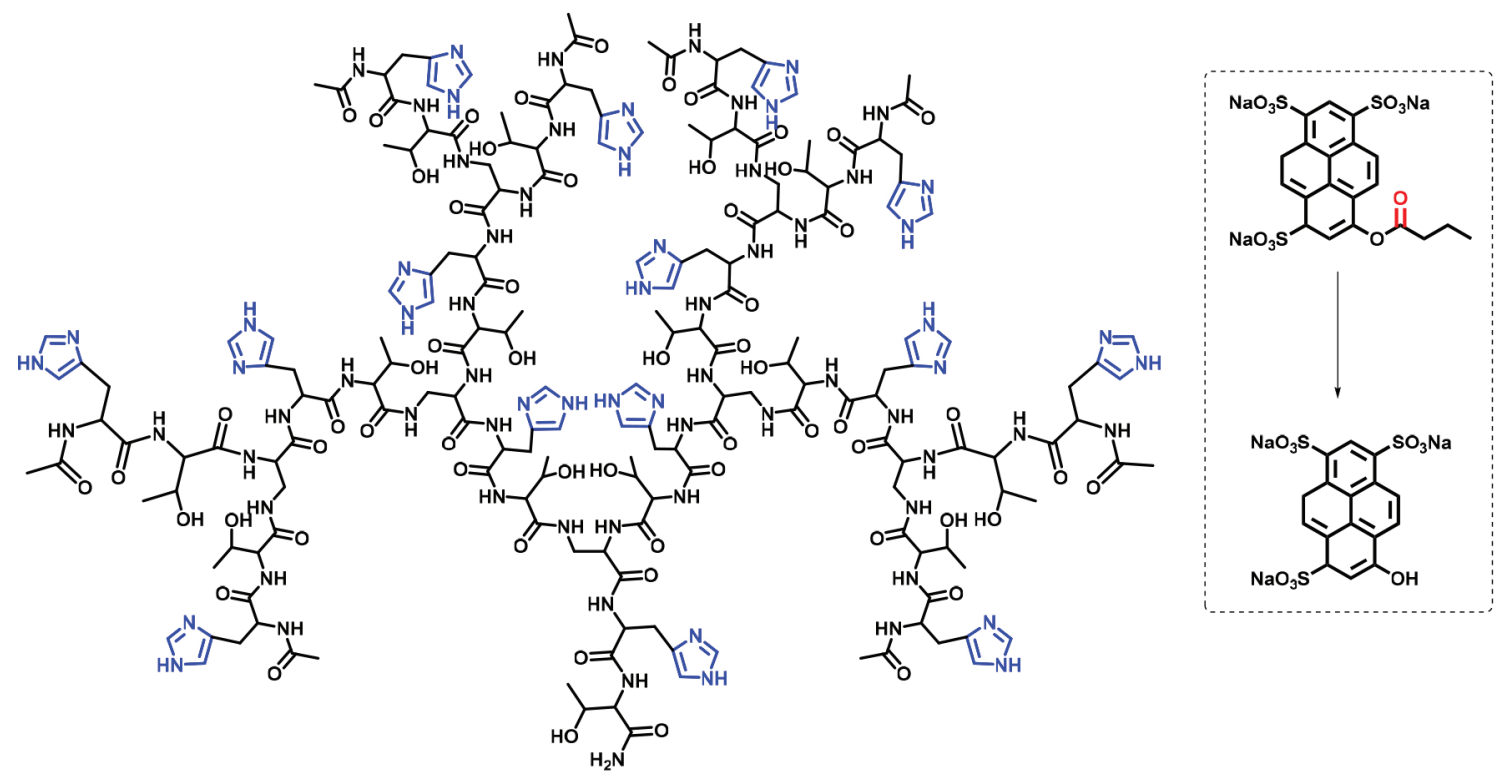

Figura 30. Dendrímero baseado em histidina utilizado como catalisador em reação de desacilação ${ }^{183}$

de filme, além da manutenção da atividade catalítica após vários ciclos de uso. ${ }^{185}$ Nanotubos de carbono (NTC) magnéticos também foram funcionalizados com IMZ, que além dos altos incrementos catalíticos na decomposição do Paraoxon na ordem de $10^{7}$ vezes apresentam a característica de serem facilmente removidos do meio reacional com um imã. ${ }^{186}$ Catalisadores derivados de lixo agrícola também foram obtidos. De fato, a casca de arroz, um derivado celulósico, é um dos maiores resíduos da agroindústria e com o objetivo de agregar valor a esse resíduo, o mesmo foi funcionalizado com IMZ e utilizado como catalisador em reações de desfosforilação. ${ }^{184}$ Para esse caso também a atividade catalítica se mostrou bastante alta, promovendo a clivagem do Paraoxon com incremento catalítico de $10^{7}$ vezes, sob condições brandas $\left(30^{\circ} \mathrm{C} \mathrm{e} \mathrm{pH} 8,5\right)$. A goma arábica, um biopolímero, quando funcionalizado com IMZ apresentou incrementos catalíticos de $10^{5}$ vezes para a degradação do DEDNPP, sendo capaz de, inclusive, quebrar o DNA plasmídico, evidenciando o potencial dos biopolímeros funcionalizados como enzimas artificiais. ${ }^{187}$

Além disso, o uso de materiais como o grafeno/NTCs permitem que outras potencialidades desses materiais possam ser exploradas como a condutividade, facilitando o seu uso em aplicações eletroquímicas como sensores. ${ }^{189}$ Por outro lado, os usos de biomateriais como a casca de arroz ou a goma arábica tornam o catalisador biocompatível e promovendo materiais que são resíduos industriais, considerados lixo, em materiais nobres.

Outra característica interessante do IMZ é ser capaz de formar estruturas chamadas de líquidos iônicos (LI) devido a sua capacidade de comportar cargas positivas. Os LI baseados em IMZ (IMZLI) têm, de forma geral, os dois nitrogênios substituídos por cadeias alifáticas e dessa forma uma carga positiva permanente, contra balanceada por um contra-íon como o cloreto, por exemplo. A química dos IMZLI apresenta bastante potencial e ultrapassa o escopo dessa revisão, entretanto vale ressaltar que reações de desfosforilação em IMZLI tem sido descritas na literatura, mais uma vez revelando a versatilidade dessa estrutura. ${ }^{190-192}$ Entretanto, diferente do apresentado até aqui, a reatividade dessas estruturas não está relacionada a catálise ácida, básica ou nucleofílica do grupo IMZ uma vez que ambos os nitrogênios estão substituídos por grupos alquila. Nesse caso, outro nucleófilo é adicionado ao meio reacional, o LI tem um grupo nucleofílico ou então o próprio contra-íon atua como nucleófilo. Assim, a eficiência do LI está relacionada a outros fatores intrínsecos da estrutura. Por exemplo, já foi observado que o carbono 2 do IMZ do LI, através de ligações de hidrogênio pode ativar o centro eletrófilo e por efeitos de polaridade atrair o mesmo, sendo um dos fatores que contribuem para acelerar as reações. ${ }^{191}$

De maneira geral, observa-se que o IMZ tem sido amplamente explorado em diversos sistemas catalíticos complexos e possuem de fato enorme potencial. Além dos sistemas discutidos acima ainda há inúmeros outros descritos na literatura baseados em IMZ, incluindo modelos para reações especificas, como miméticos de enzimas naturais das RNases, ${ }^{193-200}$ esterases, ${ }^{201}$ hidrolases ${ }^{202,203} \mathrm{e}$ fosfotriesterase. ${ }^{204}$ Ainda, tem-se a funcionalização com derivados de IMZ de aptâmeros do DNA, ${ }^{205}$ pillarenos, ${ }^{206}$ nanopartículas magnéticas, ${ }^{207}$ nanoparticulas, ${ }^{208-210}$ e polimeros impressos. ${ }^{211}$

\section{PERSPECTIVAS E RECENTES AVANÇOS}

Historicamente o grande interesse pela química dos compostos derivados de IMZ foi impulsionado pela compreensão da atividade
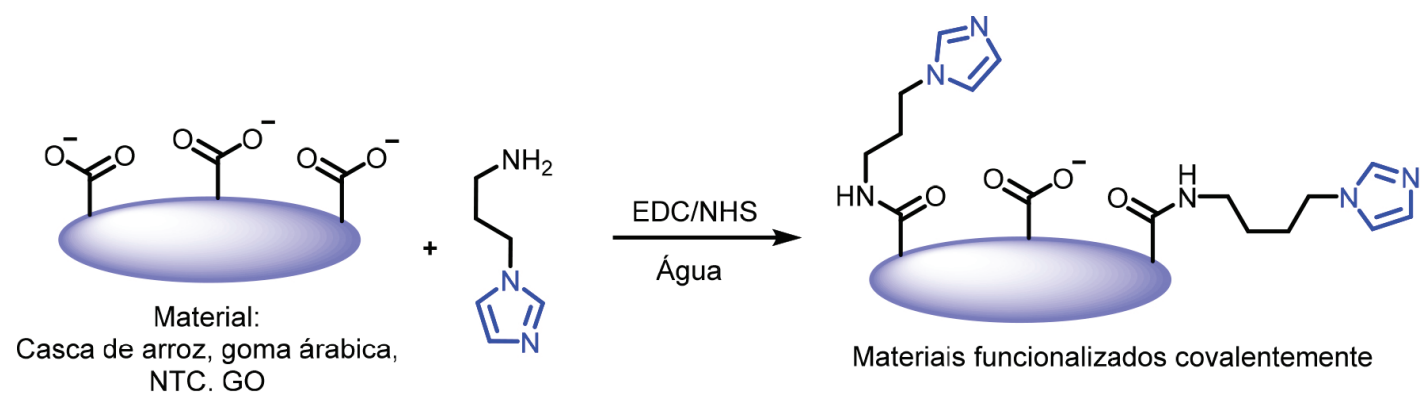

Materiais funcionalizados covalentemente

Figura 31. Rota de funcionalização dos materiais via método de ativação da carboxila EDC/NHS ${ }^{188}$ 
biológica dos seus derivados e, posteriormente, a elucidação da atividade das enzimas que continham o aminoácido histidina em seu sítio catalítico alavancou esses estudos. De fato, as propriedades físicoquímicas fazem do IMZ um composto ímpar, um exímio catalisador. O entendimento claro da atuação do IMZ em suas mais diferentes faces abre inúmeras possibilidades, desde a compreensão de que forma ele atua na natureza até a projeção de catalisadores homogêneos baseado em moléculas pequenas ou catalisadores heterogêneos quando o mesmo é combinado com polímeros, biopolímeros, materiais, nanopartículas e etc. Nesse sentido, é possível observar que a química dos compostos derivados de IMZ, apesar dos enormes avanços, ainda tem muito a ser explorada, por exemplo, questões relacionadas ao tautomerismo, basicidade, efeitos dos substituintes, efeitos do solvente e mecanismos de reação, nas mais variadas classes de reações.

Os sistemas catalíticos desenvolvidos nos últimos anos baseados em IMZ seguem mostrando que os mesmos são capazes de efetuar múltiplas catálises acida, básica e nucleofílica, promissores para resolver muitos problemas modernos como a detoxificação de pesticidas/armas químicas e desenvolvimento de sensores para substâncias tóxicas. A compreensão de como o IMZ atua nesses sistemas é imprescindível uma vez que um catalisador muitas vezes não é eficiente para duas substâncias análogas, ou ainda os produtos de reação não podem apresentar maior toxicidade que seus precursores,

Nesse sentido, essa revisão buscou dar um panorama do quão atual segue a química do IMZ e como a combinação de suas propriedades únicas com materiais modernos pode potencializar ainda mais sua atividade. Assim, podemos observar que o desenvolvimento desses sistemas deverá resultar em um aumento da eficiência dos mesmos o quão melhor consigamos compreender como a química dos derivados de IMZ funciona.

A fascinante química do IMZ, apesar de antiga, ainda é muito promissora e pode levar ao desenvolvimento de mais e melhores catalisadores, aperfeiçoando ainda mais o "par perfeito" entre o IMZ e a catálise, partindo dos mais diversos campos como a ciência básica ao desenvolvimento de materiais avançados.

\section{AGRADECIMENTOS}

Os autores agradecem à UFPR, Instituto Nacional de Ciência e Tecnologia em Nanomateriais de Carbono (INCT-Nanocarbono), Coordenação de Aperfeiçoamento de Pessoal de Nível Superior (CAPES- AUXPE e Código de Financiamento 001)), CNPq, PhosAgro/UNESCO/IUPAC, Fundação Araucária e L'OréalUNESCO-ABC. E.S. Orth agradece F. Nome (in memoriam) por ter lhe apresentado a química do imidazol.

\section{REFERÊNCIAS}

1. Debus, H.; Justus Liebigs Ann. Chem. 1858, 107, 199.

2. Verma, A.; Joshi, S.; Singh, D.; J. Chem. 2013, 2013, 12.

3. Evjen, S.; Fiksdahl, A.; Pinto, D. D.; Knuutila, H. K.; Int. J. Greenhouse Gas Control 2018, 76, 167.

4. Joule, J. A.; Mills, K.; Heterocyclic chemistry; 5th ed.; Wiley: Hoboken, 2009.

5. Hofmann, K.; Imidazole and its derivatives; Interscience Publishers: New York, 1953.

6. Clayden, J.; Greeves, N.; Warren, S.; Wother, P.; Organic Chemistry; $1^{\text {st }}$ ed.; Oxford University Press: New York, 2001.

7. Conway, B. E.; Ayranci, G.; Ayranci, E.; Z. Phys. Chem. 2003, 217, 315.

8. Orth, E. S.; Almeida, T. G.; Silva, V. B.; Oliveira, A. R. M.; Ocampos, F. M. M.; Barison, A.; J. Mol. Catal. A: Chem. 2015, 403, 93.

9. Matuszak, C.; Matuszak, A.; J. Chem. Educ. 1976, 53, 280.

10. de Vries, A. H.; van Duijnen, P. T.; Biophys. Chem. 1992, 43, 139.
11. Aguayo, R.; Arias, F.; Cañete, A.; Zuñiga, C.; Castro, E. A.; Pavez, P.; Santos, J. G.; Int. J. Chem. Kinet. 2013, 45, 202.

12. Ten, G. N.; Burova, T. G.; Baranov, V. I.; J. Struct. Chem. 2007, 48, 623.

13. Cosby, T.; Holt, A.; Griffin, P. J.; Wang, Y.; Sangoro, J.; J. Phys. Chem. Lett. 2015, 6, 3961 .

14. Kikalishvili, T. J.; Kereselidze, J. A.; Chem. Heterocycl. Compd. 2002, 38, 1069.

15. Hickman, B. S.; Mascal, M.; Titman, J. J.; Wood, I. G.; J. Am. Chem. Soc. 1999, 121, 11486.

16. Tatara, W.; Wójcik, M. J.; Lindgren, J.; Probst, M.; J. Phys. Chem. A 2003, 107, 7827.

17. Kumar, M.; Venkatnathan, A.; J. Phys. Chem. B 2015, 119, 3213.

18. Scheiner, S.; Yi, M.; J. Phys. Chem. 1996, 100, 9235.

19. Nesmeyanov, A. N.; Zavelovich, E. B.; Babin, V. N.; Kochetkova, N. S.; Fedin, E. I.; Tetrahedron 1975, 31, 1461.

20. Chen, H.; Yan, T.; Voth, G. A.; J. Phys. Chem. A 2009, 113, 4507.

21. Green, H.; Day, A. R.; J. Am. Chem. Soc. 1942, 64, 1167.

22. Gupta, R. R.; Kumar, M.; Gupta, V.; Heterocyclic chemistry; $1^{\text {st }}$ ed.; Springer: Berlin, 1998.

23. Richaud, A.; Barba-Behrens, N.; Méndez, F.; Org. Lett. 2011, 13, 972.

24. Sundberg, R. J.; Martin, R. B.; Chem. Rev. 1974, 74, 471.

25. Verma, R. K.; Aggarwal, M.; Bansal, M.; Kaur, I. P.; Synth. Commun. 2007, 37, 1977.

26. Pradhan, K.; Tiwary, B. K.; Hossain, M.; Chakraborty, R.; Nanda, A. K.; RSC Adv. 2016, 6, 10743.

27. Maxut, A.; Noziere, B.; Fenet, B.; Mechakra, H.; Phys. Chem. Chem. Phys. 2015, 17, 20416.

28. Darby, W. J.; Lewis, H. B.; Totter, J. R.; J. Am. Chem. Soc. 1942, 64, 463.

29. Sorrell, T. N.; Allen, W. E.; J. Org. Chem. 1994, 59, 1589.

30. Krall, J.; Brygger, B. M.; Sigurðardóttir, S. B.; Ng, C. K.; Bundgaard, C.; Kehler, J.; Nielsen, B.; Bek, T.; Jensen, A. A.; Frølund, B.; ChemMedChem 2016, 11, 2299.

31. Glachet, T.; Marzag, H.; Saraiva Rosa, N.; Colell, J. F.; Zhang, G.; Warren, W. S.; Franck, X.; Theis, T.; Reboul, V.; J. Am. Chem. Soc. 2019, 141, 13689.

32. Toummini, D.; Tlili, A.; Berges, J.; Ouazzani, F.; Taillefer, M.; Chem. Eur. J. 2014, 20, 14619.

33. Lantos, I.; Zhang, W. Y.; Shui, X.; Eggleston, D. S.; J. Org. Chem. 1993, 58, 7092 .

34. Rossa, T. A.; Fantinel, M.; Bortoluzzi, A. J.; Sá, M. M.; Eur. J. Org. Chem. 2018, 2018, 4171.

35. Gilan, M. M.; Khazaei, A.; Sarmasti, N.; Res. Chem. Intermed. 2019, 1.

36. Green, J. P.; Prell, G. D.; Khandelwal, J. K.; Blandina, P.; Agents Actions 1987, 22, 1 .

37. Haas, H. L.; Sergeeva, O. A.; Selbach, O.; Physiol. Rev. 2008, 88, 1183.

38. Fox, S. W.; Chem. Rev. 1943, 32, 47.

39. Rani, N.; Sharma, A.; Gupta, G. K.; Singh, R.; Mini-Rev. Med. Chem. 2013, 13, 1626.

40. Lefranc, F. Y., P.; Brotchi, J.; Kiss, R.; Int. J. Oncol. 2006, 28, 1021.

41. Gaba, M.; Mohan, C.; Med. Chem. Res. 2016, 25, 173.

42. Lassila, J. K.; Zalatan, J. G.; Herschlag, D.; Annu. Rev. Biochem. 2011, 80,669 .

43. Westheimer, F. H.; Science 1987, 235, 1173.

44. Kamerlin, S. C. L.; Sharma, P. K.; Prasad, R. B.; Warshel, A.; Q. Rev. Biophys. 2013, 46, 1.

45. Cleland, W. W.; Hengge, A. C.; FASEB J. 1995, 9, 1585.

46. Dzeja, P. P.; Terzic, A.; J. Exp. Biol. 2003, 206, 2039.

47. Saenger, W.; Principles of Nucleic Acid Structure; Springer: New York, 1984.

48. Raines, R. T.; Chem. Rev. 1998, 98, 1045.

49. Westheimer, F. H.; ACS Symp. Ser. 1992, 486, 1. 
50. Attwood, P. V.; Piggott, M. J.; Zu, X. L.; Besant, P. G.; Amino Acids 2007, 32, 145.

51. Machado, V. G.; Nome, F.; Quim. Nova 1999, 22, 351.

52. Admiraal, S. J.; Herschlag, D.; J. Am. Chem. Soc. 1999, 121, 5837.

53. Cleland, W. W.; Hengge, A. C.; Chem. Rev. 2006, 106, 325.

54. Latip, W.; Knight, V. F.; Abdul Halim, N.; Ong, K. K.; Mohd Kassim, N. A.; Yunus, W.; Zin, W. M.; Noor, M.; Aminah, S.; Ali, M.; Catalysts 2019, 9, 671.

55. Raushel, F. M.; Holden, H. M.; Adv. Enzymol. Relat. Areas Mol. Biol 2000, 74, 51.

56. Meng, Z.; Yamazaki, T.; Sode, K.; Biotechnol. Lett. 2003, 25, 1075.

57. Wilson, C.; Cooper, N. J.; Briggs, M. E.; Cooper, A. I.; Adams, D. J.; Org. Biomol. Chem. 2018, 16, 9285.

58. Caldwell, S. R.; Raushel, F. M.; Biotechnol. Bioeng. 1991, 37, 103.

59. Kirsch, J. F.; Clewell, W.; Simon, A.; J. Org. Chem. 1968, 33, 127.

60. Domingos, J. B.; Longhinotti, E.; Machado, V. G.; Nome, F.; Quim. Nova 2003, 26, 745.

61. Delfino, R. T.; Ribeiro, T. S.; Figueroa-Villar, J. D.; J. Braz. Chem. Soc. 2009, 20, 407 .

62. Kirby, A. J.; Nome, F.; Acc. Chem. Res. 2015, 48, 1806.

63. Wolfenden, R.; Snider, M. J.; Acc. Chem. Res. 2001, 34, 938.

64. Liu, C.; Wang, M.; Zhang, T.; Sun, H.; Coord. Chem. Rev. 2004, 248, 147.

65. Schowen, K.; Limbach, H.-H.; Denisov, G.; Schowen, R.; Biochim. Biophys. Acta, Bioenerg. 2000, 1458, 43.

66. Anderson, V. E.; Ruszczycky, M. W.; Harris, M. E.; Chem. Rev. 2006, 106,3236

67. Orth, E. S.; Brandão, T. A.; Milagre, H. M.; Eberlin, M. N.; Nome, F.; J. Am. Chem. Soc. 2008, 130, 2436.

68. Yang, W.; Q. Rev. Biophys. 2011, 44, 1.

69. Nelson, L. N.; Cox, M. M.; Lehninger Principles of Biochemistry, $4^{\text {th }}$ ed., W. H. Freeman: New York, 2004.

70. Fedor, M. J.; Williamson, J. R.; Nat. Rev. Mol. Cell Biol. 2005, 6, 399.

71. Smyth, D. G.; Stein, W. H.; Moore, S.; J. Biol. Chem. 1963, 238, 227.

72. Marshall, G. R.; Feng, J. A.; Kuster, D. J.; Pept. Sci. 2008, 90, 259.

73. Nogués, M. V.; Vilanova, M.; Cuchillo, C. M.; Biochim. Biophys. Acta $\mathbf{1 9 9 5}, 1253,16$

74. Steyaert, J.; Eur. J. Biochem. 1997, 247, 1.

75. Schreiber, G.; Frisch, C.; Fersht, A. R.; J. Mol. Biol. 1997, $270,111$.

76. Breslow, R.; Chapman, W. H.; Proc. Natl. Acad. Sci. U. S. A. 2007, 93, 10018.

77. Herschlag, D.; J. Am. Chem. Soc. 1994, 116, 11631

78. Sowa, G. A.; Hengge, A. C.; Cleland, W. W.; J. Am. Chem. Soc. 1997, $119,2319$.

79. Schein, C. H.; Nat. Biotechnol. 1997, 15, 529.

80. Leland, P. A.; Raines, R. T.; Chem. Biol. 2001, 8, 405.

81. Klumpp, S.; Krieglstein, J.; Biochim. Biophys. Acta, Proteins Proteomics 2005, 1754, 291.

82. Tan, E. L.; Besant, P. G.; Attwood, P. V.; Biochem. 2002, 41, 3843.

83. Puttick, J.; Baker, E. N.; Delbaere, L. T. J.; Biochim. Biophys. Acta, Proteins Proteomics 2008, 1784, 100 .

84. Reynolds, W. F.; Peat, I. R.; Freedman, M. H.; Lyerla, J. R.; J. Am. Chem. Soc. 1973, 95, 328.

85. Hultquis, D. E.; Moyer, R. W.; Boyer, P. D.; Biochem. 1966, 5, 322.

86. Matthews, H. R.; Pharmacol. Ther. 1995, 67, 323.

87. Kim, Y.; Pesis, K. H.; Matthews, H. R.; Biochim. Biophys. Acta, Mol. Cell Res. 1995, 1268, 221.

88. Kee, J.-M.; Muir, T. W.; ACS Chem. Biol. 2011, 7, 44.

89. Hultquis, D. E.; Biochim. Biophys. Acta 1968, 153, 329.

90. Klumpp, S.; Krieglstein, J.; Eur. J. Biochem. 2002, 269, 1067.

91. Robinson, V. L.; Buckler, D. R.; Stock, A. M.; Nat. Struct. Mol. Biol. 2000, 7, 626 .

92. Attwood, P. V.; Biochim. Biophys. Acta, Proteins Proteomics 2013, 1834, 470 .
93. Maeda, T.; Wurglermurphy, S. M.; Saito, H.; Nature 1994, 369, 242.

94. Besant, P. G.; Attwood, P. V.; Biochim. Biophys. Acta, Proteins Proteomics 2005, 1754, 281.

95. Robinson, V. L.; Stock, A. M.; Structure 1999, 7, R47.

96. Walinder, O.; J. Biol. Chem. 1968, 243, 3947.

97. Wieland, T.; Nurnberg, B.; Ulibarri, I.; Kaldenbergstasch, S.; Schultz, G.; Jakobs, K. H.; J. Biol. Chem. 1993, 268, 18111.

98. Cuello, F.; Schulze, R. A.; Heemeyer, F.; Meyer, H. E.; Lutz, S.; Jakobs, K. H.; Niroomand, F.; Wieland, T.; J. Biol. Chem. 2003, 278, 7220.

99. Kennelly, P. J.; Potts, M.; J. Bacteriol. 1996, 178, 4759.

100. Steeg, P. S.; Palmieri, D.; Ouatas, T.; Salerno, M.; Cancer Lett. 2003, $190,1$.

101. Matsushita, M.; Janda, K. D.; Bioorg. Med. Chem. Lett. 2002, 10, 855.

102. Cohen, P.; Eur. J. Biochem. 2001, 268, 5001.

103. McAllister, T. E.; Hollins, J. J.; Webb, M. E.; Biochem. Soc. Trans. 2013, $41,1072$.

104. Blow, D. M.; Acc. Chem. Res. 1976, 9, 145.

105. Bender, M. L.; Kezdy, F. J.; J. Am. Chem. Soc. 1964, 86, 3704.

106. Bruice, T. C.; Proc. Natl. Acad. Sci. U. S. A. 1961, 47, 1924.

107. Nothling, M. D.; Xiao, Z.; Bhaskaran, A.; Blyth, M. T.; Bennett, C. W.; Coote, M. L.; Connal, L. A.; ACS Catalysis 2018, 9, 168.

108. Gabrielli, L.; Prins, L. J.; Rastrelli, F.; Mancin, F.; Scrimin, P.; Eur. J. Org. Chem. 2020, 2020, 5044.

109. Gesser, J. C.; Yunes, S.; Clementin, R. M.; Aguilera, F. J. N.; Quim. Nova 1997, 20, 631.

110. Menger, F. M.; Acc. Chem. Res. 1985, 18, 128.

111. Lee, W.-S.; Ueno, A.; Chem. Lett. 2000, 29, 258.

112. Brown, R.; Clewley, R.; J. Org. Chem. 1987, 52, 1216.

113. Campos, R. B.; Menezes, L. R.; Barison, A.; Tantillo, D. J.; Orth, E. S.; Chem. - Eur. J. 2016, 22, 15521.

114. Brandão, T. A. S.; Orth, E. S.; Rocha, W. R.; Bortoluzzi, A. J.; Bunton, C. A.; Nome, F.; J. Org. Chem. 2007, 72, 3800.

115. Interthal, H.; Pouliot, J. J.; Champoux, J. J.; Proc. Natl. Acad. Sci. U. S. A. 2001, 98, 12009

116. Orth, E. S.; Brandao, T. A. S.; Souza, B. S.; Pliego, J. R.; Vaz, B. G.; Eberlin, M. N.; Kirby, A. J.; Nome, F.; J. Am. Chem. Soc. 2010, 132, 8513.

117. Pereira, M. S.; Murta, B.; Oliveira, T. C.; Manfredi, A. M.; Nome, F.; Hengge, A. C.; Brandao, T. A.; J. Org. Chem. 2016, 81, 8663.

118. Li, L.; Lelyveld, V. S.; Prywes, N.; Szostak, J. W.; J. Am. Chem. Soc. 2016, 138, 3986.

119. Rogers, G. A.; Bruice, T. C.; J. Am. Chem. Soc. 1974, 96, 2463.

120. Schmir, G. L.; Bruice, T. C.; J. Am. Chem. Soc. 1958, 80, 1173.

121. Felton, S. M.; Bruice, T. C.; J. Am. Chem. Soc. 1969, 91, 6721.

122. Bruice, T. C.; Sturtevant, J. M.; J. Am. Chem. Soc. 1959, 81, 2860.

123. van Der Helm, M. P.; Klemm, B.; Eelkema, R.; Nat. Rev. Chem. 2019, $3,491$.

124. Nielsen, M. F.; Ingold, K. U.; J. Am. Chem. Soc. 2006, 128, 1172.

125. Hanai, T.; J. Chromatogr. A 2003, 985, 343.

126. Bender, M. L.; Chem. Rev. 1960, 60, 53.

127. Kirsch, J. F.; Jencks, W. P.; J. Am. Chem. Soc. 1964, 86, 833.

128. Orth, E. S.; Wanderlind, E. H.; Medeiros, M.; Oliveira, P. S.; Vaz, B. G.; Eberlin, M. N.; Kirby, A. J.; Nome, F.; J. Org. Chem. 2011, 76, 8003.

129. Kirby, A.; Jencks, W.; J. Am. Chem. Soc. 1965, 87, 3209.

130. Khan, S.; Kirby, A.; J. Chem. Soc. B 1970, 1172.

131. Bender, M. L.; Turnquest, B. W.; J. Am. Chem. Soc. 1957, 79, 1656.

132. Jencks, W. P.; Carriuolo, J.; J. Am. Chem. Soc. 1960, 82, 675.

133. Bruice, T. C.; Schmir, G. L.; J. Am. Chem. Soc. 1957, 79, 1663.

134. Jencks, W. P.; Gilchrist, M.; J. Am. Chem. Soc. 1968, 90, 2622.

135. Jencks, W. P.; Carriuolo, J.; J. Biol. Chem. 1959, 243, 1272.

136. Jencks, W. P.; Oakenfull, D. G.; Salvesen, K.; J. Am. Chem. Soc. 1971 93, 188.

137. Lee, J.; Bembi, R.; Fife, T. H.; J. Org. Chem. 1997, 62, 2872. 
138. Jencks, W. P.; Oakenfull, D. G.; J. Am. Chem. Soc. 1971, 93, 178.

139. Fersht, A. R.; Jencks, W. P.; J. Am. Chem. Soc. 1970, 92, 5442.

140. Silva, V. B.; Orth, E. S.; J. Braz. Chem. Soc. 2019, 30, 2114.

141. Silva, V. B.; Nascimento, L. L.; Nunes, M. C.; Campos, R. B.; Oliveira, A. R.; Orth, E. S.; Chem. - Eur. J. 2019, 25, 817.

142. Maturano, M. D.; Bongibault, V.; Willson, M.; Klaébé, A.; Fournier, D.; Tetrahedron 1997, 53, 17241.

143. Bowden, K.; Brownhill, A.; J. Chem. Soc., Perkin Trans. 2 1997, 219.

144. Komiyama, M.; Bull. Chem. Soc. Jpn. 1990, 63, 626.

145. Oakenfull, D.; J. Chem. Soc. B 1970, 197.

146. Kunitake, T.; Horie, S.; Bull. Chem. Soc. Jpn. 1975, 48, 1304.

147. Bruice, T. C.; Schmir, G. L.; J. Am. Chem. Soc. 1958, 80, 148.

148. Campos, R. B.; Menezes, L. R.; Barison, A.; Tantillo, D. J.; Orth, E. S.; Chem. - Eur. J. 2016, 22, 15521.

149. Knowles, J. R.; Blyth, C. A.; J. Am. Chem. Soc. 1971, 93, 3021.

150. Scheffer, U.; Strick, A.; Ludwig, V.; Peter, S.; Kalden, E.; Gobel, M. W.; J. Am. Chem. Soc. 2005, 127, 2211.

151. Vlassov, V. V.; Zuber, G.; Felden, B.; Behr, J.-P.; Giegè, R.; Nucleic Acids Res. 1995, 23, 3161.

152. Niittymaki, T.; Lonnberg, H. ; Org. Biomol. Chem. 2006, 4, 15.

153. Bashkin, J. K.; Gard, J. K.; Modak, A. S.; J. Org. Chem. 1990, 55, 5125.

154. Nothling, M. D.; Xiao, Z.; Hill, N. S.; Blyth, M. T.; Bhaskaran, A.; Sani, M.-A.; Espinosa-Gomez, A.; Ngov, K.; White, J.; Buscher, T.; Sci. Adv. 2020, 6, eaaz0404.

155. Neuvonen, H.; J. Chem. Soc., Perkin Trans. 2 1987, 159.

156. Neuvonen, H.; J. Chem. Soc., Perkin Trans. 2 1995, 951.

157. Henderson, J. W.; Haake, P.; J. Org. Chem. 1977, 42, 3989.

158. Shaskus, J.; Haake, P.; J. Org. Chem. 1983, 48, 2036.

159. Wallerberg, G.; Haake, P.; J. Org. Chem. 1981, 46, 43.

160. Campos, R. B.; Santos, E. H.; Oliveira, A. R.; Ocampos, F. M. M.; Souza, B. S.; Barison, A.; Orth, E. S.; J. Org. Chem. 2015, 80, 7572.

161. Catalán, J.; Diaz, C.; Garcia-Blanco, F.; J. Org. Chem. 2001, 66, 5846.

162. Motherwell, W. B.; Bingham, M. J.; Six, Y.; Tetrahedron 2001, 57, 4463.

163. Breslow, R.; Acc. Chem. Res. 1995, 28, 146.

164. Klotz, I. M.; Royer, G. P.; Scarpa, I.; Proc. Natl. Acad. Sci. U. S. A. 1971, 68, 263.

165. Breslow, R.; Artificial Enzymes, $1^{\text {st }}$ ed., Wiley-VCH: Weinheim, 2005.

166. Sun, S. F.; Physical Chemistry of Macromolecules; 2nd ed.; John Wiley \& Sons, Inc.: New Jersey, 2004.

167. Vriezema, D. M.; Aragone`s, M. C.; Elemans, J. A. A. W.; Cornelissen, J. J. L. M.; Rowan, A. E.; Nolte, R. J. M.; Chem. Rev. 2005, 105, 1445.

168. Fouace, S.; Gaudin, C.; Picard, S.; Corvaisier, S.; Renault, J.; Carboni, B.; Felden, B.; Nucleic Acids Res. 2004, 32, 151.

169. Orth, E. S.; Campos, R. B.; J. Braz. Chem. Soc. 2016, 27, 285.

170. Khaligh, N. G.; RSC Adv. 2013, 3, 99.

171. Kunitake, T.; Okahata, Y.; J. Am. Chem. Soc. 1976, 98, 7793.

172. Giusti, L. A.; Medeiros, M.; Ferreira, N. L.; Mora, J. R.; Fiedler, H. D.; J. Phys. Org. Chem. 2014, 27, 297.

173. Gerola, A. P.; Wanderlind, E. H.; Gomes, Y. S.; Giusti, L. A.; GarcíaRío, L.; Nome, R. A.; Kirby, A. J.; Fiedler, H. D.; Nome, F.; ACS Catal. 2017, 7, 2230

174. Nothling, M. D.; Ganesan, A.; Condic-Jurkic, K.; Pressly, E.; Davalos, A.; Gotrik, M. R.; Xiao, Z.; Khoshdel, E.; Hawker, C. J.; O’Mara, M. L.; Chem 2017, 2, 732.

175. Kunitake, T.; Shinkai, S.; J. Am. Chem. Soc. 1971, 93, 4256.

176. Overberger, C.; Tomko, R.; ACS Publications: 1983.

177. Overberger, C.; Morimoto, M.; J. Am. Chem. Soc. 1971, 93, 3222.

178. Suh, J.; Oh, S.; J. Org. Chem. 2000, 65, 7534.

179. Kitano, H.; Sun, Z.; Ise, N.; Macromolecules (Washington, DC, U. S.) 1983, 16, 1823.

180. Breslow, R.; Doherty, J. B.; Guillot, G.; Lipsey, C.; J. Am. Chem. Soc. 1978, 100, 3227
181. Breslow, R.; Schmuck, C.; J. Am. Chem. Soc. 1996, 118, 6601

182. Breslow, R. E. A.; J. Am. Chem. Soc. 1989, 111, 5972.

183. Delort, E.; Nguyen-Trung, N. Q.; Darbre, T.; Reymond, J. L.; J. Org. Chem. 2006, 12, 4468.

184. Ferreira, J. G.; Orth, E. S.; J. Braz. Chem. Soc. 2017, 28, 1760.

185. Hostert, L.; Blaskievicz, S. F.; Fonsaca, J. E.; Domingues, S. H.; Zarbin, A. J.; Orth, E. S.; J. Catal. 2017, 356, 75.

186. Blaskievicz, S. F.; Endo, W. G.; Zarbin, A. J.; Orth, E. S.; Appl. Catal., B 2020, 264, 118496.

187. Ferreira, J. G.; Grein-Iankovski, A.; Oliveira, M. A.; Simas-Tosin, F. F.; Riegel-Vidotti, I. C.; Orth, E. S.; Chem. Commun. 2015, 51, 6210.

188. Orth, E. S.; Fonsaca, J. E.; Almeida, T. G.; Domingues, S. H.; Ferreira, J. G.; Zarbin, A. J.; Chem. Commun. 2014, 50, 9891.

189. de Oliveira, G. A.; Gevaerd, A.; Blaskievicz, S. F.; Zarbin, A. J.; Orth, E. S.; Bergamini, M. F.; Marcolino-Junior, L. H.; Mater. Sci. Eng. C 2020, 111140.

190. Morales, J. I.; Figueroa, R.; Rojas, M.; Millán, D.; Tapia, R. A.; Pavez, P.; Org. Biomol. Chem. 2018, 16, 7446.

191. Ferreira, J. G.; Ramos, L. M.; de Oliveira, A. L.; Orth, E. S.; Neto, B. A.; J. Org. Chem. 2015, 80, 5979

192. Kapitanov, I.; Theor. Exp. Chem. 2011, 47, 317.

193. Konevetz, D. A.; Beck, I. E.; Beloglazova, N. G.; Sulimenkov, I. V.; Sil'nikov, V. N.; Zenkova, M. A.; Shishkin, G. V.; Vlassov, V. V.; Tetrahedron 1999, 55, 503.

194. Verbeure, B.; Lacey, C. J.; Froeyen, M.; Rozenski, J.; Herdewijn, P.; Bioconjugate Chem. 2002, 13, 333 .

195. Ushijima, K.; Gouzu, H.; Hosono, K.; Shirakawa, M.; Kagosima, K.; Takai, K.; Takaku, H.; Biochim. Biophys. Acta, Gen. Subj. 1998, 1379, 217.

196. Gnaccarini, C.; Peter, S.; Scheffer, U.; Vonhoff, S.; Klussmann, S.; Göbel, M. W.; J. Am. Chem. Soc. 2006, 128, 8063.

197. Beloglazova, N. G.; Fabani, M. M.; Zenkova, M. A.; Bichenkova, E. V.; Polushin, N. N.; Sil'nikov, V. V.; Douglas, K. T.; Vlassov, V. V.; Nucleic Acids Res. 2004, 32, 3887.

198. Breslow, R.; Bovy, P.; Lipsey Hersh, C.; J. Am. Chem. Soc. 1980, 102, 2115.

199. Anslyn, E.; Breslow, R.; J. Am. Chem. Soc. 1989, 111, 8931.

200. Garipova, I. Y.; Silnikov, V.; Russ. Chem. Bull. 2002, 51, 1112.

201. Pengo, P.; Polizzi, S.; Pasquato, L.; Scrimin, P.; J. Am. Chem. Soc. 2005, 127,1616

202. Zhang, C.; Xue, X.; Luo, Q.; Li, Y.; Yang, K.; Zhuang, X.; Jiang, Y.; Zhang, J.; Liu, J.; Zou, G.; ACS Nano 2014, 8, 11715.

203. Ma, X.; Zhang, L.; Xia, M.; Zhang, X.; Zhang, Y.; J. Hazard. Mater. 2018, 355, 65 .

204. Yamazaki, T.; Yilmaz, E.; Mosbach, K.; Sode, K.; Anal. Chim. Acta 2001, 435, 209.

205. Flanagan, M. L.; Arguello, A. E.; Colman, D. E.; Kim, J.; Krejci, J. N.; Liu, S.; Yao, Y.; Zhang, Y.; Gorin, D. J.; Chem. Sci. 2018, 9, 2105.

206. Wanderlind, E. H.; Liz, D. G.; Gerola, A. P.; Affeldt, R. F.; Nascimento, V.; Bretanha, L. C.; Montecinos, R.; Garcia-Rio, L.; Fiedler, H. D.; Nome, F.; ACS Catal. 2018, 8, 3343.

207. Ruschel Campedelli, R.; Keller, M. H.; Pinheiro, G.; Campos, C. E.; Zaramello, L.; Silveira de Souza, B.; J. Org. Chem. 2019, 84, 9975.

208. Chadha, G.; Zhao, Y.; Org. Biomol. Chem. 2013, 11, 6849.

209. Pasquato, L.; Rancan, F.; Scrimin, P.; Mancin, F.; Frigeri, C.; Chem. Commun. 2000, 2253.

210. Silva, V. B.; Rodrigues, T. S.; Camargo, P. H.; Orth, E. S.; RSC Adv. 2017, 7, 40711.

211. Chen, W.; Han, D.-K.; Ahn, K.-D.; Kim, J.-M.; Macromol. Res. 2002, $10,122$. 